\title{
UN GÉNERO OLVIDADO: LOS MANUALES DE COMERCIANTES EN LA ILUSTRACIÓN TEMPRANA ESPAÑOLA (1699-1760)
}

\section{A Forgotten Genre: Merchant's Handbooks in Early Spanish Enlightenment (1699-1760)}

\author{
Jesús ASTIGARRAGA \\ Universidad de Zaragoza \\ astigarr@unizar.es
}

Fecha de recepción: 13/10/2020

Fecha de aceptación definitiva: 03/04/2021

\begin{abstract}
RESUMEN: Este trabajo reconstruye las líneas genealógicas principales de los manuales de comercio de la Ilustración española temprana. En él se muestra que España realizó una notable contribución, frecuentemente olvidada, a este movimiento internacional de la cultura impresa. El trabajo analiza los principales manuales de comerciantes de la época y revisa el legado depositado en el siglo XVIII por los tratados de aritmética comercial de las dos centurias previas -en particular, de los concebidos en el Reino de Castilla y la Corona de Aragón-. También estudia la pluralidad de formatos que se dieron cita bajo el título de "manuales de comerciantes" (libros de cuentas, tratados de sobre el arte de metales, etc.). En términos generales, puede afirmarse que este tipo de libros reunió una colección de conocimientos en matemáticas y en economía poco original y muy rudimentaria. Sin embargo, más allá de la historia intelectual, tuvieron una significación social y cultural muy notable y proliferaron debido a que en una Monarquía como la española no existían alternativas claras a ellos capaces de cubrir diferentes funciones culturales, sociales y profesionales, más allá de las estrictamente educativas.
\end{abstract}

Palabras clave: Ilustración española; circulación internacional de las ideas; print culture; matemáticas aplicadas; diseminación de la información; educación. 
ABSTRACT: This article systematically reconstructs the main genealogy of the merchant's handbooks during the early Spanish Enlightenment. It shows that Spain made a frequently forgotten but not insignificant contribution to this international print culture movement. The article analyses the main merchants' handbooks of the day as well as reviewing the legacy handed down to the eighteenth century by sixteenth and seventeenth century Spanish commercial arithmetic -especially that rooted in Castile and the Crown of Aragon-. It also studies the different formats taken by these handbooks (accounting books, treatises on metal assaying, etc.). In general terms it can be said that these books were collections of rudimentary and barely original knowledge about mathematics and economics. However, beyond the intellectual history context, they had considerable social and cultural significance and proliferated because in a Monarchy like Spain there was no clear alternative to them that was capable of fulfilling several cultural, social and professional functions, beyond the strictly educational.

Key words: Spanish Enlightenment; international circulation of ideas; print culture; applied mathematics; dissemination of information; education.

\section{INTRODUCCIÓN (*)}

A lo largo de los siglos XVI y XVII, los manuales de comerciantes brotaron en toda Europa con una virulencia extraordinaria ${ }^{1}$. Estas obras, con precedentes en los libros de ábaco y de la pratica della mercatura del Medievo italiano ${ }^{2}$, disfrutaron de una enorme heterogeneidad interna. Adoptaban la forma de tablas de equivalencias, prontuarios, libros de cuentas o guías de legislación. Su mayor emblema fueron los manuales sobre aritmética comercial y contabilidad utilizados en los escritorios, academias privadas y otros centros de enseñanza informal en la educación de comerciantes y contadores. En este sentido, aunque su contenido económico fuera muy rudimentario, cumplían una función esencial en la difusión

* Este trabajo se integra en el Proyecto de Investigación H2020-115261RB-I y H26_20D. Agradezco a Elena Ausejo por las sugerencias recibidas para su mejora. Una versión más reducida del mismo se encuentra en Astigarraga, Jesús. A Unifying Enlightenment. Institutions of Political Economy in Eighteenth-Century Spain (1700-1808). Leiden-Boston: Brill Publishers, 2021, pp. 47-68.

1. Durante el período 1500-1549 se publicaron alrededor de 1400 manuales, lo cual contrasta con los más de 1900 que vieron la luz entre 1650 y 1699; vid. KAISER, Wolfgang. "Ars Mercatoria. Möglichkeiten und grenzen einer analytischen bibliographie und datenbank". En Hoock, Johan; JEANNIN, Pierre y KAISER, Wolfgang (eds.). Ars Mercatoria. Handbücher und Traktate für den Gebrauch des Kaufmanns, 1470-1820. Paderborn: Schöningh, 2001, vol. 3, pp. 1-36; Hooch, Johan; JeAnnin, Pierre y KAISER, Wolfgang (eds.). Ars Mercatoria. Handbücher und Traktate für den Gebrauch des Kaufmanns, 1470-1820. Paderborn: Schöningh, 1991-2001, vol. 1, pp. 364 y ss.; y, adicionalmente, Hoock, Jochen. "Discours commercial et économie politique en France au XVIII siècle: l'échec d'une synthèse». Revue de Synthèse, 1987, 108(1), pp. 58-60.

2. SChumpeter, Joseph A. History of Economic Analysis. New York: Oxford University Press, 1954, pp. 156-157. 
social de los conocimientos mercantiles. Esos libros recogían tanto conocimiento proposicional acerca del comercio - pesos, medidas, cambios y monedas; geografía comercial; legislación y ética mercantiles- como conocimiento prescriptivo -aritmética aplicada y contabilidad; prácticas mercantiles; training vocacional-. También incluían habitualmente guías para el aprendizaje de las artes y oficios ${ }^{3}$. Desde comienzos del siglo XVI, crecieron exponencialmente como una expresión notable de la print culture a medida que el tráfico comercial alcanzaba las colonias y el acceso a la información -y la consiguiente reducción de los costes de transacción- se convertía en la mejor garantía del éxito comercial. En Gran Bretaña este tipo de publicaciones cuajó como un género característico durante las décadas del cambio de los siglos XVII y XVIII, y creció vertiginosamente desde entonces ${ }^{4}$. No obstante, en su codificación internacional desempeñó un papel muy notable Le parfait négociant (1675) de Jacques Savary. Aceptado como formato standard de los manuales de comerciantes, no solo generó su propia genealogía en Francia -La Porte, Larue, etc.-, sino que rompió fronteras 5 . Pronto hubo de competir con los manuales enraizados en la pujante experiencia comercial holandesa: el Traité général de commerce (1700) de Samuel Ricard, Le négoce d'Amsterdam (1723) de su hijo Jean-Pierre Ricard y otros similares elaborados por otros compatriotas franceses -Huet, Le Moine de l'Espine, etc.-. Todo ello estimuló en el siglo XVIII la activa producción nacional de manuales sobre trade, commerce, commercio y también sobre comercio, pues, como se explica a continuación, la contribución de España a este movimiento de escala internacional propio de la print culture y virtualmente olvidado no fue en absoluto desdeñable.

\section{De PÉREZ de Moya A Corachán}

La aritmética comercial del setecientos español fue, en buena medida, una prolongación de la de los dos siglos previos, especialmente, de la concebida durante la etapa monetaria de la España de los Austrias que Hamilton denominó de «bronce», dominada por la decadencia económica y el desorden monetario ${ }^{6}$. Este

3. Cole, Arthur H. The Historical Development of Economic and Business Literature. Boston: Baker Library, Harvard Graduate School of Business Administration, 1957, pp. 8-10.

4. Glaisyer, Natasha. The Culture of Commerce in England, 1660-1720. Suffolk: The Boydell Press, 2006, pp. 100-142; RAvEn, James. Publishing Business in Eighteenth-Century England. Suffolk: The Boydell Press, 2014, pp. 180-205.

5. Este vademécum de factura colbertista conoció entre 1765 y 1800 una treintena de ediciones y fue traducido en Inglaterra, Holanda, Alemania o Italia. La diseminación de su contenido se produjo también a través de obras compilatorias y diccionarios; vid. Hoock, Johan. "Le phénomène Savary et l'innovation en matière commerciale en France aux XVII ${ }^{\mathrm{e}}$ et XVIII ${ }^{\mathrm{e}}$ siècles». En KINTZ, Jean-Pierre (ed.). Innovations et renouveaux techniques de l'Antiquité à nos jours. Strasbourg: Oberlin, 1989, pp. 113123; Hoock, Jeannin y KaISER, Ars Mercatoria, 1991-2001, vol. 2; Cole, The Historical, 1957, pp. 15-16.

6. Hamilton, Earl. War \& Prices in Spain, 1651-1800. New York: Russell \& Russell, 1947. 
último era debido, principalmente, a la autonomía de que disfrutaban los viejos reinos en la Monarquía "compuesta" de los Austrias ${ }^{7}$. La tratadística de ese período se ajustó a las tres grandes áreas monetarias entonces activas: Castilla, a la que se asociaban el País Vasco y las colonias; Navarra; y los territorios de la Corona de Aragón, cada uno de ellos con sus especificidades propias ${ }^{8}$. Los manuales de este extenso período fueron profusamente reeditados en el siglo XVIII. Si existe uno que trasladó los conocimientos de la aritmética comercial desde la Baja Edad Media hasta la Ilustración, fue la Aritmética práctica y especulativa (1624) del eclesiástico andaluz y bachiller de la Universidad de Salamanca Juan Pérez de Moya (1512?-1596). Prototipo de la cultura científica renacentista, este tratado presentaba las matemáticas como una ciencia y un arte a un mismo tiempo. Estas pertenecían, junto a la astronomía, la música o la geometría, al grupo selecto de artes liberales. Al lado de la retórica o la dialéctica, contribuían decisivamente a cimentar el bien común: "El arte no da para engañar sino para excusar el engaño»". De hecho, sin ellas, las monarquías, incluida la española, padecerían una "perpetua confusión»" Sus aplicaciones al contexto mercantil poseían ventajas indiscutibles en el ámbito moral, pues servían para "sujetar a los tratantes de ruin conciencia»; pero también en el político, dado que apuntalaban los contratos, las herencias, los tributos y otros elementos que daban fundamento al orden civil. En suma, su utilidad social era indiscutible. Las matemáticas alumbraban los principios "conocidos y otorgados» de ese orden civil, cuya naturaleza no era natural, sino artificial. Por este motivo, la única manera de acceder a ellos era la educación. De hecho, solo un correcto conocimiento de los fundamentos matemáticos garantizaba su adecuada aplicación práctica. Esto se extendía a esos elementos de la vida mercantil que daban sustento al orden civil. La fundamentación matemática y sus aplicaciones iban de la mano en este prolijo manual de comerciantes destinado a formar a profesores de matemáticas.

La Aritmética de Pérez de Moya recorría la numeración, las cuatro reglas, la regla de tres, la geometría práctica, las progresiones, los números cuadrados y las raíces (libros I, II, III, IV y V); además, más allá de las bases del cálculo, abordaba también la regla de la cosa mayor o álgebra (libro VII). De manera ejemplar, la aplicación de la teoría matemática al mundo mercantil atravesaba todo el texto. Su

7. Hamilton, War, 1947, pp. 9-35. Sobre los manuales españoles de ese período, vid. LóPEZ PIÑERO, José María. Ciencia y técnica en la sociedad española de los siglos XVI y XVII. Barcelona: Labor, 1979, pp. 168-178, y GARCía GUERRA, Elena María. «Los manuales de mercaderes y contadores durante la Edad Moderna». En Alvar, Alfredo (ed.). Las Enciclopedias en España antes de l'Encyclopédie. Madrid: CSIC, 2009, pp. 319-333.

8. Grafe, Regina. Distant Tyranny. Market, Power, and Backwardness in Spain, 1650-1800. Princeton-Oxford: Princeton University Press, 2012, pp. 132-133.

9. PÉREZ DE Moya, Juan. Aritmética práctica y especulativa (1562). Barcelona: Rafael Figueró, 1703 , p. 350.

10. PÉREZ de Moya, Aritmética, 1562/1703, p. 344. 
primer libro ya incluía ejemplos de juros, censos y tipos de interés, y también de reducción de monedas, pesos y medidas. Ello permitía a Pérez de Moya hacer uso de estas magnitudes en los ocho libros posteriores. Esta visión aplicada llegaba incluso al álgebra. Pero, junto a todo ello, Pérez de Moya dedicaba uno de sus libros a enseñar a contar sin pluma en la reducción de las monedas castellanas (libro VI), y otro, a las monedas, pesos y medidas de la Antigüedad y a su equivalencia con las castellanas (libro VIII). La culminación de este magnífico tratado, obra de un excelente matemático, era un elocuente diálogo entre dos estudiantes acerca de la utilidad las matemáticas, que incluía, además de nuevos ejemplos, todo tipo de ejercicios recreativos de cálculo (libro IX). Todo ello redundaba en las bondades didácticas del texto, algo propio de quien probablemente se dedicó a la enseñanza privada de las matemáticas y diseñó su libro para divulgar su conocimiento.

La sombra de Pérez de Moya alcanzó a tres prestigiosos manuales de comerciantes de los siglos XVI y XVII que fueron reeditados en el XVIII. Obras del valenciano, asentado en Sevilla, Jerónimo de Santa Cruz; el valenciano Jerónimo Cortés, y el catalán Andrés Puig, a través de ellos se dilató en el tiempo la espléndida tradición de aritmética aplicada de la Corona de Aragón ${ }^{11}$. Se trató de textos de enseñanza, a pesar de que, a diferencia de Puig y Cortés, ambos maestros de matemáticas, Santa Cruz fue probablemente comerciante. A diferencia de la obra de Pérez de Moya, ceñida al ámbito castellano, esos textos aparecían adaptados a los usos mercantiles de los contextos en que fueron elaborados: la doble experiencia valenciana y sevillana (Santa Cruz), la ciudad de Barcelona (Puig) y «nuestra patria y Reino de Valencia» (Cortés).

Sus singularidades alcanzaban el plano teórico. El manual de Cortés no incluyó nociones de álgebra y la geometría se incorporó a él en la edición de 1724. El de Santa Cruz tampoco trataba el álgebra, pero se iniciaba con un capítulo sobre el número, ausente en el libro de Pérez de Moya. El de Puig era sin duda el de impronta más teórica: dos de sus seis libros estaban dedicados a álgebra, pero ambos aparecían casi desnudos de aplicaciones al ámbito mercantil. Precisamente, esta cuestión de la dialéctica entre la teoría y sus campos de aplicación delineó las señas de identidad de estos manuales. Santa Cruz incluyó numerosos ejemplos extraídos de los libros de mercaderes de Valencia y Sevilla, pero su Dorado era bastante limitado en el campo de las aplicaciones mercantiles. A diferencia de Pérez de Moya, solo sistematizaba ejemplos prácticos en los capítulos de matemáticas elementales, dado que las más avanzadas «rara vez se ofrecen en el arte mercantil» ${ }^{12}$. De manera singular, sus ejemplos se aplicaban todavía a enclaves

11. SALAVERT, Vicent L. "Introducción a la historia de la aritmética práctica en la Corona de Aragón en el siglo XVI». Dynamis, 1990, 10, pp. 63-91.

12. SANTA Cruz, Miguel Jerónimo de. Dorado contador. Aritmética especulativa y práctica. Contiene la fineza, y reglas de contar oro, y plata, y los aneajes de Flandes (1594). Madrid: Joaquín Ibarra, 1754, p. 240. 
perdidos del Imperio español, como Flandes, e incluían el tratamiento de los aneajes (cap. XI). Con esos ejemplos, pretendía formar contadores y mercaderes en los que "resplandeciera" la formación matemática ${ }^{13}$; pero también instruir a los ensayadores de la Casa de Contratación de Sevilla. Por esta razón, abundó en el tratamiento de los metales preciosos (libro II, cap. IX, X), y su libro fue guía en esa Casa durante décadas.

El afán de "hacer un diestro contador" recorría también la Aritmética de Puig $^{14}$. Aunque su libro incorporara usos de las contadurías y veedurías de Madrid propios de los asentistas del ejército ${ }^{15}$, sus aplicaciones se ceñían principalmente a los «mercaderes y negociantes» de Barcelona, en particular, a los del textil. El contraste en ello era muy acusado con el de Cortés. Su manual iba destinado a «todo género de tratantes y mercaderes ${ }^{16}$. Sus innumerables ejemplos alcanzaban a la milicia, los eclesiásticos, los agentes del mundo rural y una gama muy amplia del artesanado y el comercio del menudeo (plateros, sastres, carniceros, taberneros y un largo etc.). Su libro radiografiaba así la rica estratificación social del comercio valenciano. Los ejemplos exhibían los intercambios de bienes agrarios (arroz, aceite o trigo) en el interior del Reino de Valencia y las compraventas con Aragón, Mallorca, Andalucía y otros reinos de la España de los Austrias. Pero el sentido general del libro lo orientaban los intereses del comercio al por mayor, en particular, del textil y la seda, las dos ramas de la especialización regional. En él se mostraba el extenso hintherland del comercio valenciano y la diversidad de mercaderes y de sus formas de asociación, incluidas las más maduras: dedicaba un capítulo a las compañías de mercaderes y factores ${ }^{17}$. Esta pluralidad, que constituía su materia prima, se trasladaba también al plano didáctico. A diferencia de Puig y Santa Cruz, su manual era un auténtico compendio de todo tipo de fórmulas didácticas: pláticas, ejemplos, problemas, preguntas y respuestas y juegos matemáticos; en sus últimos capítulos recuperaba el método de diálogo entre un maestro y su discípulo.

Esta acomodación de los manuales a los distintos contextos mercantiles explica también el plural tratamiento en ellos de las monedas, pesos y medidas. Pérez de Moya había circunscrito esta cuestión al ámbito castellano, con alguna breve incursión en las equivalencias con Portugal. Algo casi similar ocurría con el de Santa Cruz. En cambio, en Cortés y Puig aparecían los cálculos y tablas de equivalencia de monedas, pesos y medidas con los otros reinos de la España de los Austrias, normalmente, Castilla, Cataluña, Aragón, Valencia, Mallorca y Navarra. De esta

13. SANTA CruZ, Dorado contador, 1594/1753, p. 292.

14. Puig, Andrés. Aritmética especulativa y práctica y arte de álgebra (1672). Barcelona: Giralt, 1715 , p. 144 .

15. Puig, Aritmética, 1672/1715, p. 146

16. SALAVERT, Vicent L. "L'aritmetica practica de Geronimo Cortés i la vida mercantil al País Valencià a les darreries del segle XVI». Estudis. Revista de Historia Moderna, 1982, 8, pp. 105-124.

17. CORTÉs, Jerónimo. Aritmética práctica muy útil y necesaria para todo género de tratantes y mercaderes (1604). Zaragoza: Herederos de Diego Larumbe, 1724, lib. II, cap. XXIV. 
manera, ampliaban el libro VI de Pérez de Moya desde la óptica de Castilla a la interregional. Cortés dedicaba su libro IV a esta cuestión. Puig lo hacía esencialmente en sus libros II y III, en los que Cataluña aparecía como epicentro para el cálculo de los cambios con las principales plazas de comercio europeas. Pero las exigencias de mundos comerciales como el valenciano o el catalán, intensamente internacionalizados, llevaban a ambos autores a presentar tablas de equivalencia con las monedas extranjeras, algo ajeno al de Pérez de Moya. Su fuente procedía del Uso prattico dell'aritmetica (1599) del maestro de matemáticas Oberto Cantone, concebido en el mundo comercial napolitano ${ }^{18}$.

La estela de Pérez de Moya resulta algo menos evidente en el manual de Juan Bautista de Corachán (1661-1741). Su Aritmética, publicada en 1699, puede considerarse así el punto de arranque de los manuales de comerciantes de nueva factura de la Ilustración española, así como una primera manifestación de las novedades matemáticas cultivadas en ella ${ }^{19}$. Maestro en Filosofía y doctor en Teología, este catedrático de matemáticas de la Universidad de Valencia formaba parte del círculo de novatores valencianos, uno de los más activos de la primera Ilustración española ${ }^{20}$. Su Aritmética recogía así la rica herencia universitaria local de enseñanza de las matemáticas. Hubo de ser labrado en el seno de las discusiones de los novatores acerca de la nueva filosofía y el papel protagonista que en ella desempeñaban las matemáticas, así como de la importancia de difundir sus principios. En todo ello había huellas de la labor docente modernizadora del profesor Corachán. Elevándose sobre los manuales de orientación más práctica, como el de su paisano Cortés, el suyo poseía una excelente factura teórica. En él se dejaban expresas las fuentes empleadas, algo poco usual en este tipo de literatura. Esas fuentes remitían a los tratados de matemáticas clásicos y a los de la España de los siglos XVI y XVII, incluidos los de sus maestros en la Universidad de Valencia: el

18. ConTés, Aritmética, 1604/1724, p. 528; PUIG, Aritmética, 1672/1715, p. 155. Cantone será citado todavía en 1731 por José García Caballero. Todos ellos mencionaban la edición de su libro de 1675, en Venecia.

19. Sobre esta cuestión, vid. Hormigón, Mariano. "Las matemáticas en la Ilustración española. Su desarrollo en el reinado de Carlos III». En Fernández Pérez, Joaquín y González Tascón, Ignacio (eds.). Ciencia, técnica y Estado en la España ilustrada. Zaragoza: Ministerio de Educación y Ciencia, 1990, pp. 265-278, y AUSEJO, Elena, «Las matemáticas en la Ilustración hispana: estado de la cuestión». En AstigarRaga, Jesús; López-CORdón, María Victoria y URKia, José María (eds.). Ilustración, ilustraciones. San Sebastián, 2009, vol. II, pp. 693-713.

20. LóPez PiÑERo, Ciencia y técnica, 1979, pp. 444-449. Sobre la figura de Corachán, vid. LóPEZ Piñero, José María y Navarro Brotons, Víctor. Història de la ciéncia al País Valencià. Valencia: Generalitat Valenciana, 1995, pp. 236-246. Las dudas que suscitaba entre estos autores el escaso sentido innovador de su obra han sido solventadas por PéREZ MAGALlón, Jesús. Construyendo la modernidad: la cultura española en el tiempo de los novatores (1675-1725). Madrid: CSIC, 2002, pp. 126-131. Otras miradas sintéticas sobre el mundo de los novatores españoles en MEsTre, Antonio. Despotismo e Ilustración en España. Barcelona: Ariel, 1976, y LAfuente, Antonio y PESET, José Luis. "Las actividades e instituciones científicas en la España ilustrada». En Sellés, Manuel; PESET, José Luis y LAFuente, Antonio (eds.). Carlos III y la ciencia de la Ilustración. Madrid: Alianza, 1988, pp. 30-37. 
prestigioso cartógrafo Tomás Vicente Tosca fue el censor de su Aritmética. También su Proemial era notable. Se dedicaba a la historia de las matemáticas -también el de Cortés lo hacía, pero más sucintamente- y a una indagación histórica sobre las monedas, pesos y medidas del mundo clásico. El libro se singularizaba así por su impronta académica y su utilidad para los estudiosos de las «sagradas escrituras, historiadores y autores profanos ${ }^{21}$. No obstante, su destinatario principal eran los profesores de matemáticas: Corachán planteaba sus tesis desnudas "de todo el rigor matemático, para que las puedan entender los principiantes y no olvidando que las han de leer los maestros" ${ }^{22}$.

La impronta académica de este manual era visible en otras facetas, como en su afán didáctico. Sus siete libros aparecían repletos de ejercicios y culminaban en un apéndice de «juegos por números y otras cosas curiosas». Todo ello referido al comercio. Corachán había adelantado al inicio de su texto las monedas, pesos y medidas usuales en Castilla y la Corona de Aragón, si bien defendiendo la conveniencia de establecer un sistema único de pesos y medidas. Algunos de sus ejemplos remitían a los usos mercantiles valencianos, pero, a diferencia de Cortés, ello no definía el perfil de un manual que estaba destinado a superar las fronteras del Reino de Valencia. No obstante, su ambicioso esquema teórico suponía, en algún sentido, también su principal debilidad. Los capítulos dedicados a las primeras bases del cálculo se presentaban muy equilibrados en la ilustración de la teoría con ejemplos dedicados al «trato común de compras, ventas, ganancias, trueques, compañías etc. [que] se dice mercantil, porque principalmente aprovecha a los mercaderes ${ }^{23}$. Pero, como en el manual de Puig, ese equilibrio se desvanecía a medida que el libro se introducía en las matemáticas avanzadas. Corachán defendía de manera pionera el uso de la nomenclatura decimal y llevaba su manual hasta los logaritmos, «una de las grandes invenciones de este siglo» ${ }^{24}$. Pero sus dos últimos libros carecían ya de ejemplos: el álgebra servía poco para el "trato mercantil $»^{25}$. En la misma medida en que él mostraba las infinitas posibilidades del arte noble de las matemáticas en sus aplicaciones a la armonía o la música, alejaba su libro de sus potenciales lectores. A pesar de ello, su Aritmética fue reeditada en 1719,1735 y 1757 , la segunda con la advertencia de que sus equivalencias monetarias habían quedado obsoletas. Antes se había cerrado el ciclo de los manuales de Cortés (1724) y Puig (1745). La suerte de los de Santa Cruz y Pérez de Moya fue distinta. Las cinco ediciones dieciochescas del primero -la última en 1794- se explican por su uso en la Casa de Contratación sevillana. El ciclo del segundo

21. Corachán, Juan Bautista. Aritmética demostrada teórico-práctica, para lo matemático, y mercantil: explicanse las monedas, pesos, y medidas de los hebreos, griegos, romanos, y de estos reinos de España, conferidos entre sí (1699). Barcelona: Pablo Campins, 1735, Prólogo.

22. Corachán, Aritmética, 1699/1735, Prólogo.

23. CORACHÁN, Aritmética, 1699/1735, Prólogo.

24. Corachán, Aritmética, 1699/1735, pp. 456-457.

25. Corachán, Aritmética, 1699/1735, p. 418. 
autentifica su condición de manual matriz, cuya influencia se percibe tanto en sus trece ediciones a lo largo del siglo -la última en 1798- como en una estructura interna que dominó los manuales españoles del mismo. En suma, la aritmética comercial procedente de los Austrias siguió muy viva durante el setecientos español.

\section{DE CORACHÁN A BORDÁZAR}

La producción de manuales de comercio no se interrumpió durante la guerra de Sucesión. Una vez solventado el caos monetario generado por esta -durante ella hubo emisión de moneda por parte de los dos bandos y además en el borbónico el numerario francés corrió como moneda de curso legal-, con la caída de las aduanas entre Castilla y los territorios aragoneses y la supresión en estos de su autonomía comercial y monetaria, a raíz de la promulgación de los Decretos de Nueva Planta, Felipe V dio los primeros pasos para la creación de un sistema monetario unificado ${ }^{26}$. Un importante emblema del mismo fue la fundación en 1730 de la Junta de Moneda, que fue fusionada de inmediato con la Junta de Comercio y acaparó la jurisdicción de lo relativo al numerario. Antes, ya en 1718 y en 1726, se había procedido a la retirada de las acuñaciones manipuladas en la guerra y del numerario de vellón de la etapa foral, con el fin de sustituirlo por una nueva moneda de cobre para todas las provincias. Asimismo, durante 1709 y 1738 se asistió a una ininterrumpida cadena de medidas legislativas destinadas a estabilizar el sistema monetario y a que este lograra solventar un problema estratégico: armonizar la disposición de plata para los intercambios en el mercado interior con su exportación, al ser imprescindible para saldar el déficit anual crónico de la balanza comercial. Esas medidas estabilizadoras eran en esencia una prolongación de la reforma decretada en Castilla en 1680 y 1686 por Carlos II, cuando, para evitar la inflación de la moneda de vellón, esta fue retirada de la circulación y se instauró el doble sistema de la plata. Ya con Felipe V, este sistema quedó institucionalizado en 1709 y 1716, bajo la división de una plata "antigua» o "nacional», exportable, y otra "provincial", destinada a grandes pagos en el comercio interno y con un valor intrínseco inferior a la primera en un cuarto. Otras leyes sirvieron para estabilizar estas dos platas con el oro y con el vellón de cobre, que era usado en el comercio de menudeo ${ }^{27}$. Como sostuvieron Hamilton y Vilar, estas medidas consolidaron un

26. Hamilton, War, 1947, pp. 36-54; Vilar, Pierre. Oro y moneda en la historia, 1450-1920. Barcelona-Caracas-México: Ariel, 1969, pp. 329-339; Bernal, Antonio Miguel. España, proyecto inacabado. Costes/beneficios del imperio. Madrid: Marcial Pons, 2005, pp. 318-322; PÉrEz SARRIón, Guillermo. La península comercial. Mercado, redes sociales y Estado en España en el siglo XVIII. Madrid: Marcial Pons, 2012, pp. 279-292; Grafe, Distant tyranny, 2012, pp. 132-137.

27. De acuerdo con los autores de la nota previa, diversas leyes revalorizaron las monedas de oro respecto a las de plata (1726), las de plata "nacional» respecto a las de carácter "provincial» (1728) y la plata respecto al vellón (1737). El déficit creciente de plata, debido a que era exportada 
período monetario de "estabilidad" y de "recuperación", que se extendió durante las escasas y continuistas políticas monetarias adoptadas por Fernando VI ${ }^{28}$. Pero todo ese período no fue de auténtica unificación, sino que, en palabras de Grafe, supuso "proveer de un pilar para la estabilidad monetaria» ${ }^{29}$.

Este escenario tuvo un efecto notable en los manuales de comercio. A su tradicional función de alfabetización comercial, se sumó entonces la de ser un instrumento clave en la transmisión de la información sobre las reformas y sus efectos en las equivalencias monetarias. España carecía, como Gran Bretaña, de una estructura parlamentaria que ejerciera de altavoz público de las leyes y se hallaba también alejada de otras monarquías absolutas, como la francesa, que disponía de una prensa activa y una Junta de Comercio centralizada y muy operativa ${ }^{30}$. Por ello, la literatura para comerciantes mostró en ese período toda su naturaleza versátil, en el seno de la print culture, para activar esa función de diseminación de la información. Aproximaba las pragmáticas al público, y así, en suma, salía en apoyo de la soberanía real. Así lo muestran los textos más significativos de ese período, comenzando por los del ensayador García Caballero, un auténtico inspirador de las primeras reformas monetarias de Felipe $\mathrm{V}^{31}$.

A favor de esta función jugaba el hecho de que los manuales editados después de la guerra mantuvieran su dimensión local. Más allá de la lentitud con la que se materializó el afán centralizador consustancial a las Nuevas Plantas ${ }^{32}$, ello evidenciaba que la política borbónica nunca resolvió plenamente el problema de

masivamente, obligó a crear moneda de oro de poco valor nominal, con cambio fijo respecto al vellón y como supletoria de la plata (1738).

28. Hamilton, War, 1947, pp. 58-62.

29. GRAFE, Distant tyranny, 2012, p. 137.

30. Sobre la tardía creación de la prensa económica en el siglo XVIII español, puede verse AsTIGARragA, Jesús. "Prensa económica de la Ilustración española (1758-1792)». Studia Historica. Historia Moderna, 2018, 40(2), pp. 199-232.

31. Vid., entre otros, García CABAllero, José. Breve cotejo, y balance de las pesas, y medidas de varias naciones, reinos, y provincias, comparadas, y reducidas a las que corren en estos reinos de Castilla. Madrid: Viuda de Francisco del Hierro, 1731, pp. 186 y ss.; BordázAr de ARTAZu, Antonio. Proporción de monedas, pesos y medidas, con principios prácticos de aritmética y geometría para su uso. Valencia: Imprenta de Antonio Bordázar, 1736, pp. 96-99; BordázAR DE ARTAZU, Antonio. Reducción de monedas antiguas, y corrientes de toda Europa, sacada del libro de monedas, pesos, y medidas, escrito por Antonio Bordázar de Artazu. Según el nuevo aumento de la plata y con tarifas convenientes. Valencia: Simón Faure, 1736; Tramullas y FerReras, José. Prontuario y guía de artífices plateros, en que se dan reglas para ligar, religar y abonar y reducir cualesquiera cantidad de oro y plata a la ley y quilate que su S. M. [...] manda en la Real Pragmática de 28 de febrero de 1730. Madrid: Herederos de Francisco del Hierro, 1734; MUÑOZ DE AMADOR, Bernardo. Arte de ensayar oro y plata, con breves reglas para la teórica y la práctica, en la que se explica también el oficio de ensayador y marcador mayor de los reinos. Madrid: Antonio Marín, 1755, pp. 7-12.

32. Vid., por ejemplo, García CÁRCEL, Ricardo. Felipe $V$ y los españoles: una visión periférica del problema de España. Barcelona: Plaza y Janés, 2002; AlBAREDA, Joaquim. Felipe Vy el triunfo del absolutismo. Cataluña en un conflicto europeo (1700-1714). Barcelona: Generalitat de Catalunya, 2002; y DuBET, Anne. «El gobierno de las haciendas reales hispánicas en el siglo XVIII: dinámicas de 
la falta de un mercado español unificado. Grafe ha explicado recientemente que, más allá de las causas tradicionalmente aducidas -aduanas interiores, baja densidad de población o altos costes de transporte-, ello fue debido a la fragmentación jurisdiccional ocasionada por la falta de una jerarquía política bien definida, lo cual benefició la autonomía de las ciudades y de diversas instituciones, sobre todo, las forales vasco-navarras y otras de la periferia peninsular ${ }^{33}$. A pesar de ello, el siglo XVIII supuso un avance en la reducción de la segmentación de los mercados. Enfrentado a la historiografía que retrasaba ese fenómeno al siglo XIX, Llopis ha mostrado, utilizando como índice de medición el precio del grano en el mercado interior, que ese proceso integrador fue previo y secular ${ }^{34}$, algo que ha sido confirmado, con notables matices, por Grafe, utilizando como sistema de medición alternativo el precio del bacalao. A ello hay que unir, como estudió Ringrose $^{35}$, la lenta aparición de regiones económicas, no coincidentes estrictamente con los viejos reinos históricos, constituidas a partir de sistemas urbanos, cuya continuidad es perfectamente visible en el siglo XIX. En efecto, más recientemente, Pérez Sarrión ha confirmado que durante el siglo XVIII un signo claro de esa integración económica fue la eclosión de estas regiones económicas polarized y especializadas, que brotaron del aprovechamiento de las ventajas comparativas y se estructuraron a partir de una o dos ciudades, normalmente portuarias, con mercados estables y con un hinterland comercial amplio ${ }^{36}$. Pues bien, estos sistemas urbanos emergieron también como los principales lugares productores de manuales de comercio. Estos fueron publicados en Zaragoza, Valencia, Barcelona, Sevilla, Cádiz, Bilbao o Madrid, lugares donde era más fácil acceder a la información comercial -incluso de manera oral-, eran centros de la print culture y se asentaban las redes mercantiles que dominaban la actividad de esas regiones económicas. Así se fueron consolidando genealogías de manuales que respondían a las singularidades de los usos de escala urbana o regional del comercio, siguiendo una secuencia que, partiendo de la herencia de los Austrias, no se interrumpirá a lo largo del siglo XVIII. La historia de esta tratadística es en buena medida la de ese agregado de tradiciones locales.

Ahora bien, en la segunda y tercera décadas del siglo XVIII cambió notablemente la percepción de la herencia recibida. Como hemos visto, los manuales

los reformismos borbónicos». Magallánica, 2018, 5(9), pp. 48-57. [https://fh.mdp.edu.ar/revistas/index. $\mathrm{php/magallanica/article/view/3122].}$

33. Grafe, Distant tyranny, 2012, por ejemplo, pp. 238-240.

34. Llopis, Enrique. «España, la 'revolución de los modernistas' y el legado del Antiguo Régimen». En Llopis, Enrique (ed.). El legado del Antiguo Régimen en España. Barcelona: Crítica, 2004, pp. 32-39; Llopis, Enrique y SOTACA, Sonia. "Antes, bastante antes: la primera fase de la integración del mercado español de trigo, 1725-1808». Historia Agraria, 2005, 36, pp. 225-262.

35. Ringrose, David R. España, 1700-1900: el mito del fracaso. Madrid: Alianza, 1996.

36. PÉrez SARrión, La península, 2012, pp. 35-48, 63-66. Sobre el papel de las ciudades en la fragmentación de la unidad económica, ver GRAFE, Distant tyranny, 2012, pp. 165-189. 
precedentes, desde Pérez de Moya a Corachán, eran tratados de aritmética, estructurados como tales, pero con un contenido comercial normalmente muy difuso o, sencillamente, inexistente. La denuncia de las deficiencias de este modelo para la adecuada formación de los comerciantes caracterizó la tratadística de esas décadas, aun sin aparente conexión entre sus autores. Uno de los primeros fue el sacerdote y jurista Manuel de Zubiaur (1660-?). Su Aritmética, publicada en Bilbao en 1718, iba avalada por la dedicatoria a un miembro de una familia de la alta nobleza española, Joaquín Ponce de León, duque de $\operatorname{Arcos}^{37}$. Su destinatario eran el profesorado de matemáticas comerciales que enseñaba en el entorno del Consulado de Bilbao, institución a la que Zubiaur se hallaba estrechamente vinculado $^{38}$. No obstante, si algo singularizaba su libro, era su extrema simplificación: la Aritmética era un compendio breve sobre aritmética elemental. Además, respondía perfectamente a los usos mercantiles de Bilbao y a la floreciente actividad que allí se desarrollaba en la exportación de lana castellana y hierro vizcaíno a las principales plazas de comercio europeas. En el manual se incluían cálculos sobre averías, fletes y otros conceptos de la actividad consular ${ }^{39}$. También numerosos ejemplos de reducir las monedas, no solo las españolas, sino las internacionales que "Corrían» en el comercio local. Por último, dada la condición foral de Bilbao, enseñaba al alumno a calcular los derechos de las mercancías en su paso por los puertos secos con destino a Castilla ${ }^{40}$.

Ese mismo afán de simplificación poseía la Aritmética del aragonés de Calatayud Francisco Javier García. Publicada en 1733, estaba ideada para maestros que enseñaran al comerciante aragonés cómo operar en el nuevo comercio sin aduanas abierto tras la Nueva Planta con Valencia, Cataluña y Castilla, y cómo sortear las barreras aún vigentes con Navarra. La función social del libro no era reducida. Además de profesor, García era examinador de maestros de la ciudad de Zaragoza. Su texto parecía así destinado a dominar la enseñanza mercantil en la ciudad, a cuyo corregidor y regidores estaba dedicado. En cuanto a su contenido, se articulaba para enseñar los rudimentos de la aritmética comercial «tan por menudo que al que fuere científico le servirá de molestia tanta nimiedad, mas al que careciese de noticias le servirá de grande gusto, no faltándole la afición ni aplicación, que sin estas no se conseguirá el fin deseado ${ }^{41}$. Por este motivo, se presentó como un diálogo entre un maestro y su discípulo. No obstante, en realidad, sus seis

37. Zubiaur, Manuel de. Aritmética práctica para instruir la juventud. Bilbao: Antonio Zafra, 1718 , p. 8.

38. Algo similar sucederá en una segunda obra publicada dos años antes, en defensa de la legitimidad de la usura o tipo de interés (BARrenechea, José Manuel. «Estudio Preliminar». En BarreneCHEA, José Manuel (ed.). Moral y economía en el siglo XVIII. Vitoria: Gobierno Vasco, 1995, pp. XL-LIII).

39. Zubiaur, Aritmética práctica, 1718, pp. 369-378.

40. Zubiaur, Aritmética práctica, 1718, pp. 351-368.

41. GARCía, Francisco Javier. Aritmética especulativa, y práctica, y arte mayor, o álgebra. Zaragoza: Luis de Cueto, 1733, "Al lector", sin paginar. 
libros poseían la misma estructura que los viejos manuales: incluían aplicaciones geométricas para agrimensores y el álgebra. Ello da a entender que el prestigio social de los manuales seguía ligado a la inclusión de secciones avanzadas de las matemáticas, aun a pesar de restringir su posible impacto pedagógico.

Un caso distinto es el de los dos manuales de Juan Antonio Taboada. Concebidos para el contexto mercantil de Madrid y Castilla, el primero, la Antorcha luciente (1729), estaba destinado a explicar la Pragmática de 1728 y a evitar los fraudes en la gestión de monedas que se cometían en el comercio madrileño, muy bien descritos en el libro. Su contenido quedó subsumido después en la Antorcha aritmética (1731). Pergeñada con un sentido más general, nacía repleto de recriminaciones. Unas apuntaban a "algunos aficionados al arte aritmético»; otras, a los maestros: habían errado al minusvalorar la práctica, "llave maestra del comercio»; por fin, autores «antiguos y modernos», como Pérez de Moya o Cortés, eran acusados de elaborar libros prolijos, confusos y repletos de voces extrañas "para el común" ${ }^{42}$, así como de proposiciones que "solo sirven para abultar los libros". Su comprensión estaba al alcance de los profesores de matemáticas, astrología o geometría, "pues pretender que ni un contador ni los mercaderes se diviertan en aprender los principales rudimentos, que necesitan los profesores de matemáticas, es casi imposible» ${ }^{43}$. Por estas razones, la Antorcha aritmética aparecía práctica, simplificada y aligerada de vocabulario. Carecía de un capítulo sobre álgebra, al no ser considerada útil para el comerciante. En cambio, poseía un extenso libro dedicado a monedas, pesas y medidas de Castilla (libro III), y tres capítulos para la enseñanza de la contabilidad del cargo y data de operaciones singulares, los usos en Madrid de la gestión de las letras de cambio y, por fin, las reglas de la venta de lana segoviana a través de Bilbao ${ }^{44}$.

La década de los años treinta fue la más prolífica de la primera mitad del siglo en la producción de manuales para comerciantes. La razón radica en las mencionadas medidas de estabilidad monetaria de 1726-1736. En esos años proliferaron los prontuarios, tablas y noticias sobre esas medidas y las nuevas equivalencias monetarias. Sus autores eran de extracción social diversa y se presentaban como auténticos servidores del rey (Crean, Aparici, etc.). Ese fue el contexto en que vio la luz el manual más importante de esa década, obra del valenciano Antonio Bordázar de Artazu (1671-1744) ${ }^{45}$. Su Proporción de monedas, pesos y medidas (1736) remitía nuevamente a la matriz de los novatores valencianos. Miembro de una familia de impresores comprometida con la difusión de sus escritos -su padre había editado el manual de Corachán-, Bordázar trató de fundar en los años cuarenta,

42. TABOADA y Ulloa, Juan Antonio. Antorcha aritmética práctica, provechosa para tratantes y mercaderes (1731). Madrid: Imprenta de José Otero, 1784, pp. 133-134, 142, 151.

43. TABOADA, Antorcha aritmética, 1731, "Al lector".

44. TABOADA, Antorcha aritmética, 1731, pp. 209-224, 370-416, 224-236, respectivamente.

45. Sobre Bordázar de Artazu, vid. López PiÑero y NAVArro Brotons, Història, 1995, pp. $226-232$. 
sin éxito, una academia de matemáticas en Valencia. Su formación multidisciplinar le llevó a redactar libros sobre ortografía, a intentar levantar la topografía del reino de Valencia y a enseñar gratuitamente aritmética, geometría y arquitectura. Todo ello dejó buena huella en su manual. Su edición fue una operación bien meditada. Su censura correspondió a una de las grandes figuras de la primera Ilustración española, Gregorio Mayans ${ }^{46}$. Como paratexto figuraba también la aprobación de Juan $\mathrm{Nebot}^{47}$. Era inusualmente larga pues defendía el uso de las matemáticas en el ámbito civil. Colaborador directo en la introducción de la filosofía cartesiana y el atomismo en la Universidad de Valencia, este doctor en ambos Derechos se presentaba bien relacionado con Tosca -su maestro en la Universidad- y Corachán. Citaba a Feijoo para arremeter contra la física aristotélica y a científicos prestigiosos, como Boeerhaave o Wolf, para persuadir sobre la primacía de las matemáticas en la filosofía natural y su valía como «espíritu de la República»: no se debería "Comerciar en la vida civil sin la aritmética, estática y geometría, que numeran, pesan y miden con equidad, proporción y conveniencia».

El texto de Nebot establecía puentes directos con el prólogo de Bordázar. En él se explicaban las aplicaciones de las distintas ramas de las matemáticas y la geometría. También se adelantaba una idea omnipresente en su libro: a las reglas invariables y de naturaleza matemática que establecían las proporciones entre diferentes magnitudes se oponían las de naturaleza "puramente civil y política", que dependían de los avatares del comercio y de las decisiones del soberano. Esto ocurría precisamente con la proporción de las monedas, pesos y medidas en el trato civil, el tema de su libro. Ello le permitía obviar en él la explicación teórica de las reglas matemáticas. Ideado, en suma, para "usar lo aprendido", su libro se limitaba a presentar los principios preliminares con «doctrina concisa de pura práctica ${ }^{48}$. Se ordenaba en tres tratados. El primero versaba sobre aritmética. El segundo, sobre geometría práctica; este era inusualmente extenso y se presentaba como un campo abierto a innumerables aplicaciones, más allá del comercio, para agrimensores, artesanos, etc. ${ }^{49}$. Por fin, el tercero abordaba las monedas, medidas y pesos. El cambio era sustancial respecto a los manuales precedentes, en cuanto que menos prolijo y muy condensado en lo relativo a la aritmética. Y ello sin renunciar a un horizonte teórico ambicioso: los logaritmos o el uso de la pantómetra y la trigonometría culminaban los tratados sobre aritmética y geometría, respectivamente.

El tercer tratado era el más extenso e innovador. Dialogaba con el manual de Corachán en sus capítulos dedicados a la historia de las matemáticas y las

46. Bordázar de ARTAZu, Proporción, 1736, p. XV.

47. Bordázar de ARTAZu, Proporción, 1736, pp. VII-XIV.

48. Bordázar de ARTAZU, Proporción, 1736, p. XXIII.

49. Incluía el extenso epígrafe sobre la policía de los alarifes de Juan Torija: Proporción, 1736, pp. $164-174$. 
monedas de la Antigüedad. Ello sucedía también respecto a la mención explícita de sus fuentes. No obstante, de manera expresa, Bordázar salía en defensa de la legislación monetaria de Felipe V (los decretos de 14 de enero de 1726 y de 8 de febrero de 1728):

Nadie podía creer que en breve tiempo se hubiera podido lograr la perfección material y la igualación intrínseca, acerca de la moneda de plata y oro en España, lo primero en la extinción de tanta moneda menuda y diminuta de plata informe, y lo segundo en el valor proporcionado al adelantamiento del comercio $^{50}$.

Con anterioridad había explicado que separar los valores extrínseco e intrínseco de las monedas iba contra "la mejor política" " ${ }^{51}$. A todo ello se añadían sus tablas de equivalencia. Eran las más completas publicadas hasta esa fecha. Bordázar realizó una investigación sistemática de las monedas, pesos y medidas de la Antigüedad y de uso corriente, abarcando todos los viejos reinos de la Monarquía (Castilla, Cataluña, Valencia, Aragón, Navarra y Mallorca) y sus equivalencias extranjeras. Aparecían con los valores previos a la reforma de 1728 e incluían las principales plazas europeas y, puntualmente, asiáticas ${ }^{52}$. Todo ello al servicio de una correcta formación del comerciante:

En la reducción y pagos de monedas que frecuentemente se hace por letras casi se desconoce el valor civil o corriente del país por la alteración que hay en los cambios, según el tiempo y falta de conducción, seguro y demás circunstancias. pero siempre es conveniente aun para disputar el interés excesivo saber qué correspondencia tienen los valores porque a estos se pueden acrecer los 2, 4, 10 o 20 por ciento de la letra de cambio. Los comerciantes tienen que tener trabajadas tarifas de reducción y valor de moneda para con las naciones con las que frecuentemente comercian, así pueden saber cuánto es el exceso y si es demasiado ${ }^{53}$.

En la calidad de su manual influyó sin duda la elección de las fuentes. Sus equivalencias monetarias conectaban con la tratadística holandesa, a través de Le négoce d'Amsterdam (ed. 1723) de J.-P. Ricard, epígono del manual de su padre, Samuel Ricard, uno de los más completos del siglo XVIII europeo. Todo ello con el afán tanto de avanzar hacia un sistema español unificado como de contribuir a una correcta formación del comerciante: en 1741 Bordázar elevaba una Proposición al rey para la introducción en la Monarquía de un patrón uniforme de medidas de nuevo cuño. De esta manera, igual que Corachán, se sumaba a la

50. Bordázar de ARTAZu, Proporción, 1736, pp. 96-99.

51. Bordázar de ARTAZu, Proporción,1736, p. 92.

52. La reforma monetaria de mayo de 1737, que volvió a reajustar el valor de la plata respecto al oro, invalidó de inmediato sus cálculos monetarios, lo cual obligó a Bordázar de Artazu a publicar un opúsculo con las nuevas equivalencias: Reducción de monedas antiguas, y corrientes de toda Europa, sacada del libro de monedas, pesos, y medidas, escrito por Antonio Bordázar de Artazu. Según el nuevo aumento de la plata y con tarifas convenientes. Valencia: Simón Faure, 1736.

53. BORdázar de ARTAZu, Proporción, 1736, p. 149. 
reclamación de la unidad monetaria y aduanera, todo un emblema entre la generación de economistas de Felipe V (Santa Cruz, Uztáriz, Zavala, Ulloa, etc.).

\section{LA REVUELTA DE LOS FINANCIEROS}

Frente al afán de redimensionar el contenido de los manuales, otros autores plantearon la necesidad de recomponerlos totalmente. Acertadamente, Anne Dubet ha identificado la existencia en el siglo XVIII español de una literatura singular, en cuanto que orientada a una amalgama heterogénea de financieros, tesoreros, contadores, asentistas y otros actores económicos similares, carentes de una entidad corporativa precisa pero cuyo training exigía algo diferente a lo que ofrecían los manuales al uso ${ }^{54}$. Esta cuestión se manifestaba con toda su crudeza en el Libro de cuentas (1704) de Martín de Ezpeleta. Contador de origen navarro y amparado en autoridades prominentes -dedicaba su trabajo al obispo de Gironda-, su obra surgió de los problemas suscitados por su trabajo de inspección en 1695 como visitador oficial del Hospital General de Zaragoza. Su libro se hallaba espoleado por la evidencia de que esos problemas no se hallaban resueltos «en ningún libro» de cuentas; en general, eran ignorados en ellos. Menos aún sucedía ello en esos «infinitos libros de aritmética, que todo lo tocan, aunque con reglas generales ${ }^{55}$; por ello, decidió moldear un libro de orientación radicalmente práctica. Como anunciaban sus paratextos ${ }^{56}$, en su Libro de cuentas se renunciaba intencionadamente a la secuencia matemática clásica. Solo se recurría a ella $-y$ siempre a la más elemental- cuando lo requería la solución de esos problemas precisos suscitados por su labor de inspección, que abarcaban desde la reducción de censos o las diferentes monedas españolas hasta el tráfico de la lana castellana. Escrito desde Aragón, en plena guerra de Sucesión, numerosas de sus páginas perdían utilidad ante el inminente cambio político. No por ello Ezpeleta fue un autor olvidado. Su Libro tuvo eco en el heterodoxo Taboada y además encendió la espita de una genealogía de libros con señas de identidad propias.

No parece casual que esa espita cobrara fuerza durante los años treinta, en plena vorágine de la publicación de manuales estándares de comercio. Entre 1734 y 1736 vieron la luz tres textos, obras de Valero Verdebel, José Fernández de Anuncibay y Félix García de la Fuente. El primero era contador mayor al servicio del conde de Aguilar, y su libro, El contador moderno (1734), contó con el apoyo de una autoridad política muy destacada, Agustín Luyando Montiano. Se trató,

54. Dubet, Anne. "Les calculs des gens d'argent: des traités d'arithmétique pour marchands et financiers en Espagne au XVIII ${ }^{e}$ siècle». En Clément, Jean-Pierre; PÉREZ, Béatrice y Rose, Sonia V. (eds.). Des marchands entre deux mondes. Paris: Université Paris Sorbonne, 2007, pp. 323-338.

55. EzPELETA, Martín de. Libro de cuentas extraordinarias. Zaragoza: Gaspar Martínez, 1704, "Al lector", sin paginar.

56. Véase la «Censura» de Iván Francisco, sin paginar. 
sin duda, de la obra de un contador muy experimentado. Su libro abundaba en el mensaje de la función social del contador como baluarte para garantizar un adecuado cumplimiento de los contratos, identificando el capital, el rédito y el precio, y a través de ello ejercer como un servidor incondicional del rey en todos los confines de la Monarquía:

Lo que se escribe y establece por la Majestad a los súbditos de una provincia principal se entiende escrito de las otras provincias... no hay capacidad para la excepción y alteración por los súbditos en dicha ley o precepto obligatorio común y general ${ }^{57}$.

No obstante, su contenido era más preciso. Su finalidad no era establecer los "principios elementales" de las cuentas ${ }^{58}$ cuanto enfrentar "las usuras en que incurren los que constituyen de nuevo [un contrato] y los engaños que se practican en los que se subrogan, adjudican y venden a vil precio "59; todo ello se hallaba suscitado por las pragmáticas de 1705 y 1727, que habían reducido el interés de juros y censos del $5 \%$ al $3 \%$. Esta cuestión no era en absoluto ajena a los otros dos textos: las Pláticas de aritmética (1734) de José Fernández de Anuncibay y la Voz aritmética (1736) de Félix García de la Fuente. Enraizados ambos en la economía castellana -el primer autor era natural de Ávila y vecino de Segovia y el segundo de Salamanca, donde seguramente trabajaba de contador-, presentaban una estructura interna muy similar: en sus primeros capítulos se recorría la aritmética elemental, hasta alcanzar las raíces. A continuación, ambos se abrían a cuestiones ajenas a los manuales al uso. En el libro de Anuncibay la regla de tres afloraba con una orientación práctica inusual en cuestiones como los valimientos de juros, cobranza de censos, diezmos, alcabalas y cientos, pujas de rentas, testamentos y reparto de bienes entre herederos. Al mismo tiempo, las últimas pláticas entre el maestro y su alumno en que consistían su libro se dedicaban a operaciones habituales entre contadores, tutores, curadores y administradores de bienes. Se acometía en ellas la explicación de los tipos de censos y los repartos testamentarios. Una extensa plática versaba sobre el arrendamiento de rentas reales, las posturas, pujas y remates; otra, sobre la cobranza de alcabalas y cientos. A esta última se adicionaban instrucciones precisas para participar en mercados y ferias o para instruir a los mancebos de mercaderes de joyas ${ }^{60}$. En una línea similar, García de la Fuente dedicaba dos libros íntegros de su obra a informaciones sobre censos y cuestiones similares, destinadas a los cosecheros de Salamanca en el cálculo de sisas e

57. VERBEDEL, Valero. El contador moderno, o sea práctica moderna de contadores, en el modo de conocer los géneros, diferencias y extracciones de la cantidad redituable, según el sentido de sus contratos. Madrid: Antonio Sanz, 1734, pp. 119-120.

58. VERBEDEL, El contador, 1734, Prólogo, sin paginar.

59. Verbedel, El contador, 1734, Prólogo, sin paginar.

60. Fernández de Anuncibay Urreta Basurto, José. Pláticas de aritmética y palestra de contadores. Divididas en tres libros. Madrid: Juan Muñoz, 1732, pp. 264 y ss., 269 y ss. Solo publicó uno de los dos volúmenes anunciados. 
impuestos, así como las reglas geométricas para la medición de las superficies de tierra $^{61}$. Desde una visión muy práctica, acometía también problemas propios de la gestión de las propiedades rurales, con una presentación minuciosa de las cuentas de la administración, el prorrateo de rentas de mayorazgos y los testamentos.

El libro de García de la Fuente inspiró el Prontuario (1757) de Diego Guardamino, oficial de la contaduría de pósitos. El libro fue elaborado con la anuencia del marqués del Campo de Villar, superintendente general de los pósitos. Su contenido reflejaba que las obras de los matemáticos de los antiguos reinos de los Austrias -Cortés, Tosca, Corachán o Puig- seguían muy vivas, pero que estaban obsoletas: Guardamino se centraba en rectificar sus datos sobre medidas y pesos con el fin de orientar una administración correcta de los pósitos del reino. Unos años antes, en 1743, Ezpeleta era citado por Andrés de León. Oficial de la tesorería del ejército y reino de Aragón, su Extracto estaba dedicado a su superior, Manuel Horcasitas. Su contenido era eminentemente castrense: rebosaba de informaciones inconexas sobre fortificaciones, cálculo temporal de los salarios militares, inválidos de guerra o quintas. También incluía tablas de reconversión de monedas, para "saber de memoria», y técnicas para leer quebrados. Construido con noticias recogidas "durante más de diez años» de hombres "prácticos y prudentes» ${ }^{62}$, su libro llevaba hasta sus últimas consecuencias la deconstrucción de los manuales al uso. Ilustraba perfectamente la genealogía de esos libros sobre el comercio cincelados desde la experiencia, cuyo perfil era esencialmente el de un manual de instrucciones. Más que transmitir saberes básicos, su función social era inventariar y difundir un conjunto de métodos, rutinas de trabajo y conocimientos técnicos suficientemente consolidados para ser difundidos socialmente y para ser aplicados de manera inmediata en múltiples actividades del comercio $^{63}$.

\section{OTRAS VÍAS DE DIVULGACIÓN MERCANTIL}

En el siglo XVIII se intensificó la publicación de libros de cuentas y tratados sobre el arte de ensayar los metales. Los primeros eran extremadamente divulgativos. Contenían tablas sobre las operaciones mercantiles más elementales, así como, habitualmente, las equivalencias de las monedas, pesos y medidas. Eran cercanos a las cartillas sobre doctrina cristiana, calendario y primeras letras, cuyos

61. García de la Fuente, Félix. Voz aritmética práctica para todos. Principios geométricos, con reglas para medir los campos, y para formar todo género de cuentas, con las circunstancias que puedan ocurrir. Salamanca: Imprenta de Santa Cruz, 1736, pp. 122-130.

62. LEÓn, Andrés de. Extracto de reducciones de monedas, de pesos, de medidas y de números quebrados, con la cuenta de raciones de armada, noticia de los individuos de un ejército, sueldos que gozan al mes, y al día e inválidos que se descuentan, con otras noticias provechosas. Zaragoza: Joseph Fort, 1743 , p. 83.

63. DuBET, "Les calculs", 2007, p. 337. 
autores solían coincidir. Frente a los manuales al uso, estaban destinados a favorecer la promoción social en las tesorerías y casas de comercio "para los que no saben contar, pues con que sepa leer y consonar los números, podrá seguir cualquier trato y contrato" ${ }^{64}$. Al mismo tiempo, eran "descanso» para el comerciante instruido, pues le permitían agilizar sus cálculos. Entre estos libros, la herencia del siglo XVII provino del Arte subtilísima (1680) del profesor de la Universidad de Salamanca Antonio Rodríguez. Destinadas solo a lo «civil» y focalizadas en Castilla, sus tablas conocieron una primera difusión en el primer tercio de siglo. Como los libros de esta naturaleza eran fácilmente amoldables a los cambios legislativos, en 1731 el original fue adaptado por Pedro Enguera -o Henguera-, maestro de matemáticas y alarife de Madrid, a las reformas monetarias de 1728 y 1731. Estas aparecían publicadas en las sucesivas ediciones, para aumentar así la confianza de sus lectores. Algo similar sucederá con la reforma de 1778, que originó un nuevo ciclo de ediciones. Ello prolongó la longevidad del Arte hasta convertirlo en el texto más reeditado de la tratadística para comerciantes del siglo XVIII: alcanzó las dos docenas de tiradas y se extendió al siglo posterior.

Más allá del ámbito castellano, otros libros de cuentas se presentaron adaptados a las demandas locales. Bartolomé Villar, eclesiástico aragonés asentado en Valencia y profesor del «trato mercantil», publicó en 1716 un Libro de cuentas. El motivo fue la inexistencia en Valencia de un maestro de aritmética comercial, algo imprescindible para "ejercitar verídicamente el trato y el contrato" ${ }^{65}$. Por ello, lo pergeñó para "todo género de mercaderes». Aunque ofreciera informaciones sobre el cercano mercado de Teruel, su marco era el reino de Valencia, en particular, su capital. Como el manual de Cortés, todavía vivo en sus ediciones, a través de tablas de tarifas y de equivalencias comerciales, aspiraba a articular la riqueza del comercio local y las transacciones entre la ciudad de Valencia y sus mercados circunvecinos. En otros casos eran las propias autoridades municipales las que tomaron la iniciativa. Andrés de Ávila, oficial del Ayuntamiento de Valencia, publicó en 1769 un libro de tablas con equivalencias internacionales de monedas, medidas y pesos destinado a los mercaderes locales ${ }^{66}$. No obstante, la auténtica especialización de la aritmética mercantil valenciana fue la industria sedera. La

64. Así rezaba el título del Libro de cuentas para todo género de mercaderes, en el que toparán, luz los que quisieren aprender de cuenta, y claridad, para los que no saben contar (Valencia: José García, 1716) de Bartolomé Villar. El mismo fin perseguía el librito de Tomás Medrano para comprar con onzas, arrobas o libras (Tablas de reducción, que comprenden cuantas comparaciones puedan hacerse entre el pie, y vara de Castilla, y pie de Rey, y toisa de París, en longitud cuadrado, y cúbico; las del peso especifico de los pies cúbicos de Castilla de agua dulce, madera de pino [...] las de la diferencia del aparente al verdadero nivel en medida de Castilla, y de París, 1748), o el de Andrés de Ávila, lleno de informaciones didácticas sobre los quebrados o la reducción de monedas (Modo fácil para la cobranza, y pago de cualquiera cantidades en los cuatro reinos de Castilla, Aragón, Valencia, y Cataluña. Valencia: Tomás Santos, 1769, pp. 110-117).

65. Villar, Libro, 1716, sin paginar.

66. Ávila, Modo fácil, 1769. Se trataba de la tercera impresión. 
genealogía la inició en 1740 Carlos Bernardo de Quirós, pero las tablas más completas se debieron al maestro de cálculo Mariano Badelles. Estaban destinadas a instruir a los oficiales de tesorería y comerciantes al por mayor y por menor, en particular, a los de la seda, en las operaciones de letras de cambio y en las conversiones de las monedas y pesos de los viejos reinos. Su Descanso de comerciantes (1754) conoció después un ciclo de nuevas ediciones, en algún caso, ampliadas, gracias al profesor de matemáticas Manuel González de la Torre (1723-1794) y al corredor de lonja y maestro torcedor Mariano Torralba. Ese ciclo se extendió hasta fin de siglo con el Libro de cuentas (1794) de González de la Torre, quien volvía a subrayar su absoluta simplicidad: para su uso no era "necesario saber aritmética o arte de contar ${ }^{67}$. Pero el declive de la industria sedera en los años finales de siglo arrastró consigo el de la plurisecular aritmética comercial valenciana ${ }^{68}$.

En el cercano Principado de Cataluña se encuentran otras pruebas de la gran versatilidad de los libros de cuentas. Allí hubo ediciones en lengua catalana de este tipo de textos. Francesc Ifern, maestro y eclesiástico -era presbítero y beneficiado de la catedral de Gerona-, publicó en 1746 un compendio de primeras bases del cálculo con aplicaciones al comercio. La razón es que los más usuales no eran comprensibles para muchos comerciantes, al estar elaborados en castellano ${ }^{69}$. Sus ediciones alternativas en Gerona, Barcelona y Tarragona, que alcanzaron el fin de siglo, reflejan que el uso de la lengua catalana en los ámbitos mercantiles se extendía a buena parte del Principado. No obstante, más exitoso que el texto de Ifern fue el Llibre facil de comptes fets. Fue publicado anónimo, por vez primera probablemente en 1703, en Gerona. Aunque encabezado con títulos diversos, era una traducción de Le Livre des comptes faits (1669) del aritmético francés, protegido de Colbert, François Barrême (1638-1703). Las tablas de la versión catalana pretendían ofrecer cobertura a todas las actividades productivas del Principado no solo para negociantes, tenderos y oficiales de tesorería, sino también incluso para «empresarios»; no obstante, había partes del libro, en concreto, las castrenses, que se presentaban en castellano. De hecho, también existen ediciones íntegras del mismo en esa lengua publicadas en Barcelona. Su producción en años alternativos en esta ciudad y Gerona es un indicio de que estaba siendo utilizado por agentes productivos diferentes, entre ellos, comerciantes y agricultores. Su prolífico y dilatado ciclo vital, que alcanzó el siglo XIX, evidencia que la producción de este tipo de textos era simple y poco costosa, debido a su formato de folleto, de pequeña

67. GONZÁlez DE LA TORRE, Manuel. Libro de cuentas hechas útil para toda clase de personas. Gerona: Jaume Bró, 1750, p. 4.

68. Cervera, Pablo. El pensamiento económico de la Ilustración valenciana. Valencia: Generalitat Valenciana, 2003, pp. 43-44.

69. IFERN, Francesc. Compendi breu de las quatre reglas generals de la arismetica practica (1746). Gerona: Narcís Oliva, 1753, "Al benévolo lector", sin paginar. 
dimensión y reducido número de hojas ${ }^{70}$. Y también seguramente un negocio infalible. Esto explica que fuera producido por editores, como los gerundenses Jaume Brò o Narcís Oliva, o por comerciantes de libros. Este fue el caso de Francisco Asensio, mercader de libros en Madrid, quien publicó en los años cincuenta diversas tablas de equivalencia de monedas ajustadas a la Pragmática de 1737.

En los tratados dedicados al arte de ensayar metales preciosos con el fin de acuñar moneda se describían las reglas y técnicas que debían respetar las casas de moneda para alcanzar la fineza establecida por ley ${ }^{71}$. De ello dependía el valor metálico de las monedas y, por tanto, el volumen de oro y plata que se ponía en circulación y se extraía al extranjero. Esta tratadística era estratégica para la Hacienda real, que ingresaba por derecho de señoreaje, y también para la Monarquía, en su condición de principal productora internacional de metales preciosos. No obstante, su tradicional "monocultivo minero" en el ámbito colonial y otras erradas políticas económicas la habían convertido en una especie de "seguro almacén" desde el cual se distribuían después por todo el mundo ${ }^{72}$. De ahí que esos tratados se hicieran eco de las quejas de los arbitristas por esas nefastas políticas ${ }^{73}$. Su origen se hallaba en el Quilatador de oro, plata y piedras (1572) del platero leonés Juan de Arfe y Villafañe. No obstante, al siglo XVIII llegaron particularmente de la mano del eclesiástico andaluz Álvaro Alonso de Barba (1569-1662). Su Arte de los metales (1640) conoció dos ediciones en el setecientos (fue editado con el Tratado de las antiguas minas de España de Alonso Carrillo y Laso), así como una circulación internacional inusual para un libro español sobre tecnología (fue objeto de numerosas traducciones al inglés, alemán y francés $)^{74}$.

Al tratarse de una manifestación de la soberanía real, esta tratadística estaba sometida a un rígido control de sus contenidos y de sus autores. Estos eran plateros que, debido a su presteza en docimasia y matemáticas, habían pasado a integrar el ente corporativo y hermético de ensayadores o marcadores de las casas

70. Tal y como se menciona en el Tyrocinio aritmético, instrucción de las cuatro reglas llanas (Zaragoza: José Fort, 1738). Este breve folleto de reglas matemáticas elementales con sucintas aplicaciones al comercio fue el primero escrito por una mujer: la aragonesa María Andrea CASAMAYOR. Hubo de esconderse bajo un seudónimo masculino (Casandro Mamés de LA MARCA y ARAIOA).

71. Sobre la abundante bibliografía acerca de las casas de moneda, vid. en particular: MURRAY, Glen. "Guía de los marcos acuñados y ensayadores de la Casa de Moneda de Madrid». Numisma, 1993, 233, pp. 295-387; PÉrEZ Sindreu, Francisco de Paula. La casa de la moneda de Sevilla. Sevilla: Universidad de Sevilla, 1991; EstradA-Rius, Albert. La casa de la moneda de Barcelona. Lleida: Pagès, 2015. Esta última versa sobre las cecas de la Corona de Aragón, para el período previo a la Nueva Planta.

72. MuÑOZ DE AMADOR, Bernardo. Arte de ensayar oro y plata, con breves reglas para la teórica y la práctica, en la que se explica también el oficio de ensayador y marcador mayor de los reinos. Madrid: Antonio Marín, 1755, p. 7. Sobre esta cuestión, vid. BERNAL, España, 2005, pp. 236-245.

73. MuÑOZ DE AMADOR, Arte, 1755, pp. 7 y ss.

74. AlONSO DE BARBA, Álvaro. Arte de los metales en que se enseña el verdadero beneficio de los de oro y plata por azogue, el modo de fundirlos todos, y cómo se han de refinar y apartar unos de otros (1640). Madrid: Bernardo Peralta, 1770; BERNAL, España, 2005, pp. 236-237. 
de moneda del Reino. Dado que la vieja prerrogativa del Consejo de Castilla para su nombramiento había pasado a la Junta de Comercio, la institución responsable desde 1730 de lo relativo a la moneda, la designación de esos profesionales quedaba en sus manos ${ }^{75}$. Asimismo, los tratados producidos por ellos debían ser publicados con su aprobación. Por ello, se limitaron a unos pocos nombres: Javier García Caballero $(1713,1731)$, José Tramullas y Ferreras $(1734,1743)$ y Bernardo Muñoz de Amador $(1741,1755)$. Los dos primeros eran oficiales mayores de la Casa de Moneda de Madrid y el tercero, de la de Barcelona, si bien terminó recalando en la de Madrid. Durante 1720-1760, los cargos principales pivotaron sobre las cecas de Sevilla -la que más metales labraba- ${ }^{76}$ y de Madrid. Su condición de funcionarios de la Junta de Comercio justificaba las dedicatorias de sus obras a Patiño (García Caballero) y Ensenada (Tramullas), autoridades que la dirigieron.

La literatura sobre el arte de ensayar metales era de naturaleza oficial, por ello no extraña que creciera al albur de las reformas de Felipe V. El funcionamiento de las casas de moneda fue estipulado en las ordenanzas de 1718, 1728 y 1730. Si la primera cedió el monopolio de la acuñación al Estado, la última centralizó las acuñaciones peninsulares de plata y oro en las casas de Madrid y Sevilla y la de cobre en Segovia, y extinguió las demás cecas castellanas (Burgos, Toledo, etc.), ya que las aragonesas ya habían sido clausuradas. Con ello se pretendía favorecer tanto la unificación monetaria y la centralización de las cecas como la mecanización de las labores, también al ámbito colonial, en particular la sustitución de la técnica del martilleo por las presas al volante. Estas obras publicitaban además las cédulas reales que establecían el valor en quilates y en dineros del oro y la plata. Fueron, en suma, un cortafuegos de las leyes monetarias de Felipe $\mathrm{V}^{77}$, a quien consideraban el auténtico artífice de esa política proteccionista, tantas veces reclamada. El correcto cumplimiento de esas leyes era esencial también desde la perspectiva del derecho de gentes, para garantizar el comercio justo con otras naciones ${ }^{78}$.

García Caballero elaboró su primer tratado en Sevilla, en 1706, en plena guerra de Sucesión, pero fue publicado en 1713, cuando esta finalizó y cinco años después de que hubiera alcanzado el puesto de ensayador de la Casa de Moneda de Madrid, estratégico en la elaboración de leyes. Dedicado a Felipe V, con su

75. MuÑoZ DE AMADOR, Arte, 1755, pp. 211-212.

76. Bernal, España, 2005, pp. 304-307.

77. Muñoz De Amador, Bernardo. Proporción aritmética-práctica de la plata. 2 vols. Madrid: Antonio Marín, 1741.

78. García Caballero, José. Breve cotejo, y balance de las pesas, y medidas de varias naciones, reinos, y provincias, comparadas, y reducidas a las que corren en estos reinos de Castilla. Madrid: Viuda de Francisco del Hierro, 1731, p. 2. Otro ejemplo de cercanía con los tratados sustancialmente jurídicos, que remitían al derecho de gentes e incorporaban información sobre equivalencias monetarias nacionales e internacionales, es DomínguEz VicENTE, José Manuel. Discursos jurídicos sobre las aceptaciones, pagas, intereses, y demás requisitos, y cualidades de las letras de cambio. Madrid: Herederos de Juan García Infanzón, 1732, pp. 491-516. 
libro pretendía reemplazar definitivamente el tratado de Arfe en la instrucción de ensayadores y marcadores. Un cuarto de siglo después, y siempre como ensayador mayor, publicó una excelente indagación histórica destinada a combatir la diversidad de pesos y medidas y favorecer las políticas unificadoras. Detrás de todo ello se hallaba la defensa de las reformas del nuevo rey, en las que había colaborado decisivamente ${ }^{79}$. También rebatía las fuentes clásicas castellanas sobre el valor de las monedas españolas y sus equivalencias internacionales: acusaba a Mariana, Covarrubias o Pérez de Moya de ser demasiado teóricos. No obstante, sus libros no fueron un caso aislado. El arte de ensayar metales escondía guías y tablas que publicitaban los cambios legislativos entre los plateros. Dado que los ensayadores eran árbitros de estos, emergía así una función social central de esta tratadística: combatir el fraude. Acerca de esta cuestión sobresalieron los tres libros del barcelonés Tramullas. Eran encargos de la Junta de Comercio para difundir las medidas reales y persuadir a los orfebres de que en el laboreo del oro y la plata respetaran la legislación y sus propias ordenanzas gremiales (1732). Trataban sencillamente de combatir la "codicia" de los fabricantes y la "falta de inteligencia" de los marcadores de oro y plata ${ }^{80}$. Tramullas era especialmente competente para ello. Además de ensayador mayor, ejercía como visitador de las platerías de la Corona de Aragón. Una de sus obras llevaba la censura del salmantino Muñoz de Amador. Precisamente, de la mano de este llegó en 1755 la síntesis principal de esta publicística singular. Para esa fecha Muñoz de Amador era un profesional muy experimentado. Tras iniciarse como platero, había sido reconocido ensayador en 1736. Diez años después se había incorporado a la Casa de Moneda de Madrid. Su Arte de ensayar oro y plata (1755) estaba dedicado a Juan Francisco Gaona, conde de Valdeparaíso. Recopilaba la teórica y práctica de la genealogía abierta por Arfe y Alonso de Barba, y culminaba en García Caballero, Tramullas y el maestro portugués Roque Francisco, a quienes, en el marco de las ordenanzas y leyes recientes, había seguido al "pie de la letra»" Gracias a este buen conocimiento de la tradición, elaboró la mejor síntesis del siglo sobre el oficio de ensayador, al cual dedicaba uno de los tres libros de su Arte.

La llegada al trono de Carlos III en 1759 ratificó la pluralidad interna que escondían los manuales de comerciantes. Buen reflejo de ello eran los libros de Miguel de Hualde y Pedro Cantos Benítez, escritos con apenas cinco años de diferencia. El primero, obra de un padre carmelita navarro, fue elaborado en forma

79. García Caballero, Breve cotejo, 1731, p. 8, 186 ff.

80. Tramullas y Ferreras, José. Guía, y desengaño, de artífices plateros, y marcadores de oro, y plata. En el cual se prescribe la obligación de los fabricantes plateros en preparar las materias de oro, y plata antes de construir con ellas las obras. Barcelona: Herederos de María Martí, 1743, "Prólogo", sin paginar. También publicó un texto sobre equivalencias de las monedas catalanas y castellanas: Puntual correspondencia, y reducción verídica de la moneda de vellón de Cataluña a la de Castilla, y la de Castilla a la de Cataluña. Madrid: Juan de Oliveras, 1734.

81. MuÑOZ DE AMADOR, Arte, 1755, pp. 4, 12-13. 
de diálogo entre un administrador y un contador lego -el propio autor- y se hallaba atravesado por la vieja preocupación escolástica por el logro de la justicia en los tratos civiles $^{82}$. En cambio, el segundo reflejaba mucho mejor la llegada de un nuevo tiempo político. Escondía, en realidad, un tratado de historia monetaria española desde la Antigüedad hasta los Borbones. Su intencionalidad política era muy clara: mostrar la ancianidad del Consejo de Castilla -al cual iba dedicadocomo órgano supremo de la Monarquía. Cantos se revolvía contra la interpretación naturalista, que despreciaba por inútiles las artes y las ciencias, especialmente la Jurisprudencia ${ }^{83}$ : esta era insoslayable para mantener las leyes de la sociedad y para que el gobierno cumpliera con su obligación de conservar la «tranquilidad, utilidad y justicia» ${ }^{84}$. Aun sin renunciar a su narrativa histórica, la segunda parte de este extenso tratado estaba destinada a informar sobre las monedas españolas antiguas, su soporte legislativo, su valor metálico y sus equivalencias recíprocas con el fin de arreglar la reducción de sus precios y contratos a la estimación de la moneda actual, lo cual convertía el libro en un tratado de historia monetaria, esencialmente desde la etapa de los romanos. En ese esquema la moneda se erigía como una prueba confirmatoria de esa vigencia plurisecular de la Monarquía española. Es claro, por tanto, que su auténtico destinatario no eran los comerciales cuanto las nuevas elites políticas reunidas en torno a Carlos III: publicado en 1763, tan solo cuatro años después de que este hubiera iniciado su reinado, el libro está imbuido de la retórica propia de esos nuevos tiempos.

\section{A MODO DE CONCLUSIONES}

Los manuales de comercio publicados en las primeras seis décadas del siglo XVIII español fueron, en general, cuerpos de conocimientos matemáticos y económicos rudimentarios y anquilosados. No solo resultaron poco innovadores -la larga sombra de Pérez de Moya está muy presente en ellos-, sino que constituyeron simples plagios o pastiches en los que solo sus títulos pretenciosos o la escasa mención a las fuentes empleadas encubrían su escasa originalidad ${ }^{85}$. No obstante, más allá de la historia intelectual, su relevancia social y cultural fue muy notable. Proliferaron porque reducían los costes de transacción e información, y también

82. Vid. el primer cuaderno de los tres que componían el libro de Miguel De HuadDE. El contador lego, especulativo y práctico, sobre varios asuntos de aritmética civil y astronómica. Madrid: Francisco Javier García, 1758.

83. CANTOS Benítez, Pedro de. Escrutinio de maravedises y monedas de oro antiguas, su valor, reducción y cambio a las monedas corrientes. Deducido de escrituras, leyes y pragmáticas antiguas y modernas de España. Madrid: Antonio Marín, 1763, p. 11

84. Cantos Benítez, Escrutinio, 1763, pp. 11-14.

85. La falta de definición sobre los derechos de autor favorecía las rutinas del hurto y el plagio; vid. Álvarez Barrientos, Joaquín. Los hombres de letras en la España del siglo XVIII. Apóstoles y arribistas. Madrid: Castalia, 2006, pp. 191-199. 
porque en una Monarquía como la española no tenían sustitutivos claros para cubrir funciones sociales imprescindibles: más allá de la educación en aritmética comercial, gracias a su enorme versatilidad, también contribuían a la diseminación de la información, la transmisión de técnicas de la experiencia profesional o la lucha contra el fraude. Esta diversidad de funciones explica la pluralidad de sus formatos, algo que en sí mismo los singulariza en el cuerpo general de la print culture, pero que, en algún sentido, también los aproxima a otro tipo de libros destinados a los comerciantes, como por ejemplo los diccionarios de comercio o de economía política ${ }^{86}$. Ahora bien, esta pluralidad no alcanzó a manuales con el perfil de los de Savary o Ricard. Pero esto se explica porque España no solo careció de una Junta de Comercio con la capacidad política de la francesa o de un centro mercantil con la pujanza de Ámsterdam, sino que, debido a su mercado económico tan fragmentado, los manuales ajustados a los usos locales resultaban más útiles que esos vademécums universales o, incluso, de dimensión nacional.

Tras repasar los autores principales de estos manuales, cabe preguntarse ahora a quiénes iban destinados. Indiscutiblemente, sus primeros lectores fueron quienes los patrocinaron. Un repaso a sus dedicatorias, de las que hemos dejado algunas muestras en las líneas precedentes, desvela la cercanía de sus autores con nobles, clérigos o altos funcionarios, que podían mantener vínculos familiares o de otra índole con el mundo del comercio o las finanzas. En esas labores de patronazgo, no solo contaba el incentivo para los autores de promocionarse en el mundo del comercio, las finanzas o la administración, sino también el interés de esas autoridades de proteger esa literatura, como una contribución personal a la Monarquía: esos libros cimentaban la "sociedad de los hombres» y el «bien público"; eran, por ello, un servicio al rey ${ }^{87}$. A partir de esos primeros lectores, podemos especular acerca de sus destinatarios finales. Zubiaur escribió su libro para maestros de matemáticas; Fernández Anuncibay, para "estudiantes novicios", y Atienza, para eludir al maestro. Todo apunta, por tanto, a un público heterogéneo, algo a lo que responde también la pluralidad de los formatos. Hemos visto que algunos textos iban destinados a profesionales especializados, como los ensayadores, y otros, a grupos sociales de baja alfabetización. No obstante, dada la complejidad de la mayoría de los libros, hubo de tratarse mayoritariamente de un público adulto y formado. Entre ellos hubieron de predominar los maestros de matemáticas, comerciantes y financieros experimentados, que pudieron emplear

86. Sobre su fortuna en la Ilustración española, vid. AstigarRagA, Jesús y ZabalzA, Juan. «Los diccionarios de Comercio y Economía en el siglo XVIII español». Revista de Historia Industrial, 2007, 35, pp. 13-46; Astigarraga, Jesús y ZabalZA, Juan. «Economía Política y Comercio en los diccionarios y la literatura enciclopédica española del siglo XVIII». Bulletin Hispanique, 2009, 111(2), pp. 387-427.

87. CREAn, Eduardo. Cálculo general de todos los cambios corrientes en estos reinos de España, con Francia, Inglaterra, Holanda, Portugal e Italia; compuesto en once cuadernos de tablas. Madrid: Francisco Martínez Abad, 1737. 
esos libros en las academias, los escritorios de sus empresas o sus casas privadas, con la ayuda de tutores.

Pero su utilidad iba más allá de sus lectores directos. Expresión singular de la eclosión de la print culture en el siglo XVIII ${ }^{88}$, estos libros acuñaban en forma impresa no solo aritmética y nociones mercantiles, sino también técnicas y rutinas del comercio. Con su incorporación a los escritorios y a las bibliotecas, todo ello se ponía al servicio de comerciantes y policy-makers, y, debido a la inexistencia de instituciones regladas de enseñanza comercial, de estadísticas oficiales y de prensa regular, se garantizaba la transmisión intergeneracional del conocimiento, su acumulación y su diseminación geográfica, aunque su escala fuera seguramente local. Además, como recordó Maravall, la sola exigencia de formar a grupos sociales en el respeto al rigor de las reglas matemáticas suponía en sí misma un rasgo de modernidad $^{89}$. Más importante aún fue que esa literatura no fue ajena a la lucha por la dignificación social del comercio. A pesar de proponer «una corta navegación en el inmenso piélago de los números» (Corachán), la aritmética comercial era "la energía de las demás ciencias» (Nebot); la "antorcha luciente» que guiaba a las naciones (Santa Cruz); la "llave maestra del comercio» (Taboada); el conjunto de "reglas que sirven al contador, como los colores lo hacen al pintor» (Santa Cruz); o, por fin, «una especie de cartabón con que se mide la verdad» (Pérez de Moya). En esos libros la actividad mecánica del comercio, estigmatizada entre los recelos sociales y las sospechas sobre su legitimidad religiosa, aparecía entrelazada con el arte "sutilísimo", noble y liberal de las matemáticas. De esta manera, cuando en las décadas medias del siglo en España se filtre la concepción de la "ciencia del comercio" como un arma poderosa para la acción política del Estado, la batalla por la dignificación del comercio se entrelazó con la idea de que unos comerciantes instruidos por medio de una educación reglada y unos manuales adecuados constituían un activo indispensable para la República. Eran, en palabras de Campomanes, las "antorchas de la economía política", esa clase de personas que animaba la circulación del Estado, "Como el corazón lo hace, dando impulso a la circulación de la sangre en el cuerpo humano» ${ }^{90}$.

88. Vid., por ejemplo, MunCK, Historia social, 2001, pp. 115-153.

89. Maravall, José Antonio. Antiguos y modernos. La idea de progreso en el desarrollo inicial de una sociedad. Madrid: Sociedad de Estudios y Publicaciones, 1966, pp. 565-567.

90. Campomanes, Pedro Rodríguez, conde de. Apéndice a la educación popular. Madrid: Antonio de Sancha, 1775-1777, vol. IV, pp. XI-XII. Sobre la suerte de los manuales de comerciantes en la Ilustración tardía española, vid. Astigarraga, A Unifiying Enlightenment, 2021, pp. 219-242. 


\section{Bibliografía}

\subsection{Sección I. Manuales de comerciantes españoles}

ALONSO DE BARBA, Álvaro. Arte de los metales en que se enseña el verdadero beneficio de los de oro y plata por azogue, el modo de fundirlos todos, y cómo se han de refinar y apartar unos de otros (1640). Madrid: Bernardo Peralta, 1770.

ASENSIO Y MEjORADA, Francisco. Nuevo uso y provechoso para reducir a reales de vellón, conforme a la Real Pragmática de 17 de mayo de 1737, todo género de moneda corriente, c. 1758.

ATIENZA, José. Método nuevo, fácil, breve, y curioso de aritmética, teórica y práctica; con el que cualquiera podrá, sin maestro, aprender a contar desde el alfabeto hasta lo más sublime de la facultad, con muchas reglas nuevas y curiosas. Madrid: Alfonso López, 1748.

Ávila, Andrés de. Modo fácil para la cobranza, y pago de cualquiera cantidades en los cuatro reinos de Castilla, Aragón, Valencia, y Cataluña. Con la correspondencia que tienen entre sí todas las monedas de oro, y plata en cada uno de ellos, y las provinciales que respectivamente usan. Valencia: Tomás Santos, 1769.

BADElles, Mariano. Descanso de comerciantes: principalmente para los que tratan con la seda. Valencia: José Tomás Lucas, 1754.

BARRÊME, François. Llibre fácil de comptes fets, ab lo qual se pot traurer tota especie de comptes de tota moneda, per enter ó trencat, tenint present los exemples que á est fi se han añadit (1703). Gerona: Jaume Brò, 1750.

BARRÊME, François. Libro de cuentas hechas: útil para toda clase de personas; sacado de las obras de Barrême. Barcelona: Francisco Genéras, 1765.

BERNALDO DE QUIRÓs, Carlos. Tabla demostrativa de diferentes sumas y cuentas, hechas para lo mercantil, principalmente para la seda. Valencia: Antonio Batle, 1740.

Bordázar de ARTAZu, Antonio. Proporción de monedas, pesos y medidas, con principios prácticos de aritmética y geometría para su uso. Valencia: Imprenta de Antonio Bordázar, 1736.

BORDÁZAR DE ARTAZU, Antonio. Reducción de monedas antiguas, y corrientes de toda Europa, sacada del libro de monedas, pesos, y medidas, escrito por Antonio Bordázar de Artazu. Según el nuevo aumento de la plata y con tarifas convenientes. Valencia: Simón Faure, 1736.

Cantos Benítez, Pedro de. Escrutinio de maravedises y monedas de oro antiguas, su valor, reducción y cambio a las monedas corrientes. Deducido de escrituras, leyes y pragmáticas antiguas y modernas de España. Madrid: Antonio Marín, 1763.

Corachán, Juan Bautista. Aritmética demostrada teórico-práctica, para lo matemático, y mercantil: explicanse las monedas, pesos, y medidas de los hebreos, griegos, romanos, y de estos reinos de España, conferidos entre sí (1699). Barcelona: Pablo Campins, 1735.

CORTÉs, Jerónimo. Aritmética práctica muy útil y necesaria para todo género de tratantes y mercaderes (1604). Zaragoza: Herederos de Diego Larumbe, 1724.

CREAN, Eduardo. Cálculo general de todos los cambios corrientes en estos reinos de España, con Francia, Inglaterra, Holanda, Portugal e Italia; compuesto en once cuadernos de tablas. Madrid: Francisco Martínez Abad, 1737.

Domínguez Vicente, José Manuel. Discursos jurídicos sobre las aceptaciones, pagas, intereses, y demás requisitos, y cualidades de las letras de cambio. Madrid: Herederos de Juan García Infanzón, 1732. 
EzPELETA, Martín de. Libro de cuentas extraordinarias. Zaragoza: Gaspar Martínez, 1704.

García, Francisco Javier. Aritmética especulativa, y práctica, y arte mayor, o álgebra. Zaragoza: Luis de Cueto, 1733.

García CABAllero, José. Teórica, y práctica de la arte de ensayar oro, plata, y vellón rico. Dánse reglas para ligar, religar, alear y reducir cualesquiera cantidades de oro, y plata a la ley del reino. Corrígense las reglas, y tablas de Juan de Arphe, y auméntase otras nuevas, para mayor claridad de los que quisieren aprender esta facultad. Madrid: Imprenta de Agustín Fernández, 1713.

García Caballero, José. Breve cotejo, y balance de las pesas, y medidas de varias naciones, reinos, y provincias, comparadas, y reducidas a las que corren en estos reinos de Castilla. Declárase también la ley, peso, y valor de algunas monedas hebreas, griegas, romanas, y castellanas, $y$ de otros reinos, y señoríos. Madrid: Viuda de Francisco del Hierro, 1731.

García de la Fuente, Félix. Voz aritmética práctica para todos. Principios geométricos, con reglas para medir los campos, y para formar todo género de cuentas, con las circunstancias que puedan ocurrir. Salamanca: Imprenta de Santa Cruz, 1736.

GONZÁLEZ DE LA TORRE, Manuel. Cartilla aritmética o rudimentos de las cuatro reglas con la reducción de monedas, pesos y medidas de los cinco reinos. Valencia: Gerónimo Conejos, 1749.

GONZÁlez De la TORRe, Manuel. Libro de cuentas hechas útil para toda clase de personas. Gerona: Jaume Bró, 1750.

GONZÁLEZ DE LA TORRE, Manuel. Instrucción para las cobranzas de letras de cambio y vales de comercio. Valencia: Francisco Burguete, 1774.

GONZÁlez de la TORRe, Manuel. Descanso de comerciantes, principalmente para los que tratan en seda, que hallarán las cuentas hechas por el precio de 10 reales la libra de seda, hasta el de 50 desde media onza, por menor, hasta 70 lib. y por mayor hasta 2000: que en el año 1754 se imprimió a nombre de Mariano Badelles; y abora nuevamente añadido por su verdadero autor Manuel González de la Torre. Valencia: Francisco Burguete, 1774.

Hualde, Miguel de. El contador lego, especulativo y práctico, sobre varios asuntos de aritmética civil y astronómica. Incluye 3 cuadernos. 1. Es útil para los pueblos, ganaderos, escribanos, contadores, moralistas, juristas y comerciantes. Madrid: Francisco Javier García, 1758.

IFERN, Francesc. Compendi breu de las quatre reglas generals de la arismetica practica: que son sumar, restar, multiplicàr y partir: ab algunas reglas necessarias per los negociants; ab una taula al fi, à rabò de tant lo any, á quant vé per lo mes y lo dia (1746). Gerona: Narcís Oliva, 1753.

La Marca y ARAIOA, Casandro Mames de (pseud. de María Andrea Casamayor). Tyrocinio aritmético, instrucción de las cuatro reglas llanas. Zaragoza: José Fort, 1738.

LEÓN, Andrés de. Extracto de reducciones de monedas, de pesos, de medidas y de números quebrados, con la cuenta de raciones de armada, noticia de los individuos de un ejército, sueldos que gozan al mes, y al día e inválidos que se descuentan, con otras noticias provechosas. Zaragoza: Joseph Fort, 1743.

Medrano, Felipe. Tablas de reducción, que comprenden cuantas comparaciones puedan hacerse entre el pie, y vara de Castilla, y pie de Rey, y toisa de París, en longitud cuadrado, y cúbico; las del peso específico de los pies cúbicos de Castilla de agua dulce, 
UN GÉNERO OLVIDADO: LOS MANUALES DE COMERCIANTES EN LA ILUSTRACIÓN...

madera de pino [...] las de la diferencia del aparente al verdadero nivel en medida de Castilla, y de París, 1748.

MuÑOZ DE AMADOR, Bernardo. Proporción aritmética-práctica de la plata. Tablas generales, en que se demuestra el peso y valor de la plata en todas leyes, reducido a las últimas, que por la Real Pragmática del año pasado de 1728 se observa; y todo puesto según práctica de ensayadores, contrastes y mercaderes, muy útil para todos los comerciantes en plata. 2 vols. Madrid: Antonio Marín, 1741.

MuÑOZ DE AMADOR, Bernardo. Arte de ensayar oro y plata, con breves reglas para la teórica y la práctica, en la que se explica también el oficio de ensayador y marcador mayor de los reinos. Madrid: Antonio Marín, 1755.

Pérez de Moya, Juan. Aritmética práctica y especulativa (1562). Barcelona: Rafael Figueró, 1703.

PUIG, Andrés. Aritmética especulativa y práctica y arte de álgebra: en la cual se contiene todo lo que pertenece al arte menor o mercantil y a las dos álgebras, racional e irracional: con la explicación de todas las proposiciones y problemas de los libros [...] de la matemática Euclides (1672). Barcelona: Giralt, 1715.

RoDríguez, Antonio. Arte sutilísima, práctica y teórica, para contar guarismo de repente. Por lo cual se harán con mucha facilidad todas las reglas y reducciones de monedas, pesos y medidas, censos, rentas, pechos, alcabalas y aduanas, a tanto por ciento, que se usan en Castilla y otros reinos. Madrid: Juan Esteban, 1719.

Rodríguez, Antonio y Enguera, Pedro. Arte útil y compendioso para facilitar el método de las cuentas de compras, ventas, censos, alcabalas, pesos, medidas y reducciones de monedas, según las Pragmáticas que se observan en este reino de Castilla y otros. Añadido nuevamente las faltas y aumentos del oro. Compuesto por el maestro Antonio Rodríguez, profesor de aritmética en la Universidad de Salamanca. Enmendado y añadido por don Pedro Enguera, maestro de matemáticas del Rey y alarife de Madrid. Añadido nuevamente las faltas del oro y de la plata (1730). Madrid, 1740.

SANTA CRUZ, Miguel Jerónimo de. Dorado contador. Aritmética especulativa y práctica. Contiene la fineza, y reglas de contar oro, y plata, y los aneajes de Flandes (1594). Madrid: Joaquín Ibarra, 1754.

TABOADA y UlloA, Juan Antonio. Antorcha luciente: que con su claridad alumbra, para registrar el más breve modo de reducir a reales de vellón doblones, y pesos efectivos de a diez reales de plata provincial (1725). Madrid: Imprenta y librería de Gabriel Ramírez, 1751.

TABOADa y Ulloa, Juan Antonio. Antorcha aritmética práctica, provechosa para tratantes y mercaderes. Instruye a los principiantes con reglas del arte menor, y muchas nuevas para reducir las monedas de Castilla unas en otras. Declara modo seguro de comerciar con dichas monedas, la cobranza de vales y letras de todas partes y otras curiosidades (1731). Madrid: Imprenta de José Otero, 1784.

TORRalba y CAmpos, Mariano. Descanso de comerciantes: principalmente para los que tratan en seda [...]: que en [...] 1754 se imprimió a nombre de Mariano Badelles y abora nuevamente añadido por Mariano Torralba y Campos. Valencia: Francisco Burguete, 1784.

Tramullas y Ferreras, José. Prontuario y guía de artífices plateros, en que se dan reglas para ligar, religar y abonar y reducir cualesquiera cantidad de oro y plata a la ley y quilate que su S. M. [...] manda en la Real Pragmática de 28 de febrero de 1730. Madrid: Herederos de Francisco del Hierro, 1734. 
TRAmullas y Ferreras, José. Puntual correspondencia, y reducción verídica de la moneda de vellón de Cataluña a la de Castilla, y la de Castilla a la de Cataluña: y asimismo la reducción legítima de todas las monedas corrientes de oro y plata, a reales de vellón de Castilla, según la realidad de su valor, con la explicación correspondiente de entrambas monedas. Madrid: Juan de Oliveras, 1734.

TRAmullas y FerReras, José. Guía, y desengaño, de artífices plateros, y marcadores de oro, y plata. En el cual se prescribe la obligación de los fabricantes plateros en preparar las materias de oro, y plata antes de construir con ellas las obras. Barcelona: Herederos de María Martí, 1743.

VERBEDEL, Valero. El contador moderno, o sea práctica moderna de contadores, en el modo de conocer los géneros, diferencias y extracciones de la cantidad redituable, según el sentido de sus contratos. Madrid: Antonio Sanz, 1734.

VILLAR, Bartolomé. Libro de cuentas para todo género de mercaderes, en el que toparán, luz los que quisieren aprender de cuenta, y claridad, para los que no saben contar. Valencia: José García, 1716.

Zubiaur, Manuel de. Aritmética práctica para instruir la juventud. Bilbao: Antonio Zafra, 1718.

\subsection{Sección II. Bibliografía secundaria}

AlBareda, Joaquim. Felipe Vy el triunfo del absolutismo. Cataluña en un conflicto europeo (1700-1714). Barcelona: Generalitat de Catalunya, 2002.

ÁlvareZ BarRientos, Joaquín. Los hombres de letras en la España del siglo XVIII. Apóstoles y arribistas. Madrid: Castalia, 2006.

AstigarRaga, Jesús. «Prensa económica de la Ilustración española (1758-1792)». Studia Historica. Historia Moderna, 2018, 40-2, pp. 199-232.

Astigarraga, Jesús. A Unifying Enlightenment. Institutions of Political Economy in Eighteenth-Century Spain (1700-1808). Leiden-Boston: Brill Publishers, 2021.

Astigarraga, Jesús y Zabalza, Juan. "Los diccionarios de Comercio y Economía en el siglo XVIII español». Revista de Historia Industrial, 2007, 35, pp. 13-46.

Astigarraga, Jesús y Zabalza, Juan. «Economía Política y Comercio en los diccionarios y la literatura enciclopédica española del siglo XVIII». Bulletin Hispanique, 2009, 111(2), pp. 387-427.

AusEjO, Elena. «Las matemáticas en la Ilustración hispana: estado de la cuestión». En AsTIGARRAGa, Jesús; López-Cordón, María Victoria y URKia, José María (eds.). Ilustración, ilustraciones. San Sebastián, 2009, vol. II, pp. 693-713.

Barrenechea, José Manuel. «Estudio Preliminar». En Barrenechea, José Manuel (ed.). Moral y economía en el siglo XVIII. Vitoria: Gobierno Vasco, 1995, pp. 9-58.

Bernal, Antonio Miguel. España, proyecto inacabado. Costes/beneficios del imperio. Madrid: Marcial Pons, 2005.

Campomanes, Pedro Rodríguez, conde de. Apéndice a la educación popular. Madrid: Antonio de Sancha, 1775-1777, 4 vols.

CERVERA, Pablo. El pensamiento económico de la Ilustración valenciana. Valencia: Generalitat Valenciana, 2003.

Cole, Arthur H. The Historical Development of Economic and Business Literature. Boston: BakerLibrary, Harvard Graduate School of Business Administration, 1957. 
UN GÉNERO OLVIDADO: LOS MANUALES DE COMERCIANTES EN LA ILUSTRACIÓN...

DuBET, Anne. «Les calculs des gens d'argent: des traités d'arithmétique pour marchands et financiers en Espagne au XVIII e siècle». En CléMent, Jean-Pierre; PÉrez, Béatrice y Rose, Sonia V. (eds.). Des marchands entre deux mondes. Paris: Université Paris Sorbonne, 2007, pp. 323-338.

DuBET, Anne. «El gobierno de las haciendas reales hispánicas en el siglo XVIII: dinámicas de los reformismos borbónicos». Magallánica, 2018, 5(9), pp. 48-57. [https://fh.mdp. edu.ar/revistas/index.php/magallanica/article/view/3122].

Dubet, Anne y SolBes, Sergio. El rey, el ministro y el tesorero. Madrid: Marcial Pons, 2019.

Estrada-Rius, Albert. La casa de la moneda de Barcelona. Lleida: Pagès, 2015.

GARCÍA CÁRCEL, Ricardo. Felipe V y los españoles: una visión periférica del problema de España. Barcelona: Plaza y Janés, 2002.

GLAISYER, Natasha. The Culture of Commerce in England, 1660-1720. Suffolk: The Boydell Press, 2006.

Grafe, Regina. Distant Tyranny. Market, Power, and Backwardness in Spain, 1650-1800. Princeton-Oxford: Princeton University Press, 2012.

Hamilton, Earl. War \& Prices in Spain, 1651-1800. New York: Russell \& Russell, 1947.

Hoock, Jochen. "Discours commercial et économie politique en France au XVIII siècle: l'échec d'une synthèse». Revue de Synthèse, 1987, 108(1), pp. 57-73.

Hoock, Johan. "Le phénomène Savary et l'innovation en matière commerciale en France aux XVII ${ }^{e}$ et XVIII ${ }^{e}$ siècles». En KINTZ, Jean-Pierre (ed.). Innovations et renouveaux techniques de l'Antiquité à nos jours. Strasbourg: Oberlin, 1989, pp. 113-123.

HOOCK, Johan; JEANNIN, Pierre y KAISER, Wolfgang (eds.). Ars Mercatoria. Handbücher und Traktate für den Gebrauch des Kaufmanns, 1470-1820. 3 vols. Paderborn: Schöningh, 1991-2001.

Hormigón, Mariano. «Las matemáticas en la Ilustración española. Su desarrollo en el reinado de Carlos III». En Fernández Pérez, Joaquín y GonzÁlez TASCón, Ignacio (eds.). Ciencia, técnica y Estado en la España ilustrada. Zaragoza: Ministerio de Educación y Ciencia, 1990, pp. 265-278.

KAISER, Wolfgang. «Ars Mercatoria. Möglichkeiten und grenzen einer analytischen bibliographie und datenbank». En Hoock, Johan; JeAnnin, Pierre y KaISER, Wolfgang (eds.). Ars Mercatoria. Handbücher und Traktate für den Gebrauch des Kaufmanns, 1470-1820. Paderborn: Schöningh, 2001, vol. 3, pp. 1-36.

LAFuente, Antonio y PeSET, José Luis. «Las actividades e instituciones científicas en la España ilustrada». En Sellés, Manuel; Peset, José Luis y Lafuente, Antonio (eds.). Carlos III y la ciencia de la Ilustración. Madrid: Alianza, 1988, pp. 29-79.

Llopis, Enrique. "España, la 'revolución de los modernistas' y el legado del Antiguo Régimen». En Llopis, Enrique (ed.). El legado del Antiguo Régimen en España. Barcelona: Crítica, 2004, pp. 11-76.

LLOPIS, Enrique y SOTACA, Sonia. "Antes, bastante antes: la primera fase de la integración del mercado español de trigo, 1725-1808». Historia Agraria, 2005, 36, pp. 225-262.

LóPeZ PIÑERO, José María. Ciencia y técnica en la sociedad española de los siglos XVI y XVII. Barcelona: Labor, 1979.

López Piñero, José María y NaVArRo Brotons, Víctor. Història de la ciéncia al País Valencià. Valencia: Generalitat Valenciana, 1995.

Maravall, José Antonio. Antiguos y modernos. La idea de progreso en el desarrollo inicial de una sociedad. Madrid: Sociedad de Estudios y Publicaciones, 1966.

Mestre, Antonio. Despotismo e Ilustración en España. Barcelona: Ariel, 1976. 
Munck, Thomas. The Enlightenment. A Comparative Social History, 1721-1724. New York: Oxford University Press, 2000 [trad. castellana: Historia social de la Ilustración. Barcelona: Crítica, 2001].

MurraY, Glen. "Guía de los marcos acuñados y ensayadores de la Casa de Moneda de Madrid». Numisma, 1993, 233, pp. 295-387.

Pérez Magallón, Jesús. Construyendo la modernidad: la cultura española en el tiempo de los novatores (1675-1725). Madrid: CSIC, 2002.

PéREZ SARRIón, Guillermo. La península comercial. Mercado, redes sociales y Estado en España en el siglo XVIII. Madrid: Marcial Pons, 2012.

PÉrez Sindreu, Francisco de Paula. La casa de la moneda de Sevilla. Sevilla: Universidad de Sevilla, 1991.

Raven, James. Publishing Business in Eighteenth-Century England. Suffolk: The Boydell Press, 2014.

RINGROSE, David R. España, 1700-1900: el mito del fracaso. Madrid: Alianza, 1996.

SALAVERT, Vicent L. "L'aritmetica practica de Geronimo Cortés i la vida mercantil al País Valencià a les darreries del segle XVI». Estudis. Revista de Historia Moderna, 1982, 8, pp. 105-124.

SALAVERT, Vicent L. «Introducción a la historia de la aritmética práctica en la Corona de Aragón en el siglo XVI». Dynamis, 1990, 10, pp. 63-91.

SCHUMPETER, Joseph A. History of Economic Analysis. New York: Oxford University Press, 1954.

VILAR, Pierre. Oro y moneda en la historia, 1450-1920. Barcelona-Caracas-México: Ariel, 1969. 